ARTICLE

\title{
Phenotypes on demand via switchable target protein degradation in multicellular organisms
}

\author{
Frederik Faden ${ }^{1,2}$, Thomas Ramezani ${ }^{3,4, \dagger}$, Stefan Mielke ${ }^{1,2}$, Isabel Almudi ${ }^{5, \dagger}$, Knud Nairz ${ }^{5, \dagger}$, Marceli S. Froehlich ${ }^{6, \dagger}$, \\ Jörg Höckendorff $6, \dagger$, Wolfgang Brandt 7 , Wolfgang Hoehenwarter ${ }^{8}$, R. Jürgen Dohmen ${ }^{6}$, Arp Schnittger $3,4,9, \dagger$ \\ \& Nico Dissmeyer $1,2,3,4,9$
}

Phenotypes on-demand generated by controlling activation and accumulation of proteins of interest are invaluable tools to analyse and engineer biological processes. While temperaturesensitive alleles are frequently used as conditional mutants in microorganisms, they are usually difficult to identify in multicellular species. Here we present a versatile and transferable, genetically stable system based on a low-temperature-controlled $\mathrm{N}$-terminal degradation signal (It-degron) that allows reversible and switch-like tuning of protein levels under physiological conditions in vivo. Thereby, developmental effects can be triggered and phenotypes on demand generated. The It-degron was established to produce conditional and cell-type-specific phenotypes and is generally applicable in a wide range of organisms, from eukaryotic microorganisms to plants and poikilothermic animals. We have successfully applied this system to control the abundance and function of transcription factors and different enzymes by tunable protein accumulation.

\footnotetext{
${ }^{1}$ Independent Junior Research Group on Protein Recognition and Degradation, Leibniz Institute of Plant Biochemistry (IPB), Weinberg 3, D-06120 Halle (Saale), Germany. ${ }^{2}$ ScienceCampus Halle-Plant-based Bioeconomy, Betty-Heimann-Strasse 3, D-06120 Halle (Saale), Germany. ${ }^{3}$ University Group at the Max Planck Institute for Plant Breeding Research (MPIPZ), Max Delbrück Laboratory, Carl-von-Linné-Weg 10, D-50829 Cologne, Germany. ${ }^{4}$ University of Cologne, Institute of Botany III, Biocenter, Zülpicher Str. 47 b, D-50674 Cologne, Germany. ${ }^{5}$ Institute of Molecular Systems Biology (IMSB), Swiss Federal Institute of Technology (ETH), Wolfgang-Pauli-Strasse 16, CH-8093 Zurich, Switzerland. ${ }^{6}$ Institute for Genetics, Biocenter, University of Cologne, Zülpicher Straße 47a, D-50674 Cologne, Germany. ${ }^{7}$ Computational Chemistry, Department of Bioorganic Chemistry, Leibniz Institute of Plant Biochemistry (IPB), Weinberg 3, D-06120 Halle (Saale), Germany. ${ }^{8}$ Proteomics Unit, Leibniz Institute of Plant Biochemistry (IPB), Weinberg 3, Halle (Saale) D-06120, Germany. ${ }^{9}$ Département Mécanismes Moléculaires de la Plasticité Phénotypique, Institut de Biologie Moléculaire des Plantes du CNRS, IBMP-CNRS, Unité Propre de Recherche 2357, Conventionné avec l'Université de Strasbourg, 12, rue du Général Zimmer, Strasbourg F-67000, France. †Present addresses: The Queen's Medical Research Institute, MRC Centre for Inflammation Research, The University of Edinburgh, 47 Little France Crescent, Edinburgh EH16 4TJ, UK (T.R.); Andalusian Centre for Developmental Biology (CABD), Universidad Pablo de Olavide, Ctra. Utrera Km. 1, 41013 Seville, Spain (I.A.); Novino Slowdrink GmbH, Blümlisalpstrasse 31, CH-8006 Zürich, Switzerland and Inselspital Bern, Freiburgstrasse 10, CH-3010 Bern, Switzerland (K.N.); Grünenthal Innovation-Early Clinical Development, Grünenthal GmbH, Zieglerstraße 6, D-52078 Aachen, Germany (M.S.F.); UCB BIOSCIENCES GmbH, Alfred-Nobel-Straße 10, D-40789 Monheim, Germany (J.H.); Department of Developmental Biology, Biozentrum Klein Flottbek, University of Hamburg, Ohnhorststrasse 18, D-22609 Hamburg, Germany (A.S.). Correspondence and requests for materials should be addressed to N.D. (email: nico.dissmeyer@ipb-halle.de).
} 
T he classical way to generate temperature-sensitive alleles comprises random mutagenesis followed by large-scale screens at different temperatures. This procedure is usually limited to fast-growing single-celled organisms where mutant populations can be analysed simultaneously at restrictive and permissive temperatures. Major problems in using temperaturesensitive alleles are their generation, identification, establishment and leakiness. An alternative way to generate heat-sensitive mutants is to use a temperature-inducible $\mathrm{N}$-degron (td), where a protein of interest (POI) is fused to a portable N-terminal degradation cassette ${ }^{1}$. However, to date this technique has been solely used in unicellular eukaryotes in a temperature range impractical for most multicellular organisms. We show how to efficiently circumvent these limitations by using a novel portable td fusion protein to render the levels of active POIs conditional.

Generally, degradation signals within a protein sequence that make it short-lived in vivo or in vitro are called 'degrons' ${ }^{2}$, and an 'N-degron' ${ }^{3}$ is an amino-terminal ( $\mathrm{N}$-terminal) degron, which relates the metabolic stability of a protein to the identity of its amino-terminal residue depending on the $\mathrm{N}$-end rule pathway ${ }^{4}$. The $\mathrm{N}$-end rule pathway is part of the ubiquitin $(\mathrm{Ub}) /$ proteasome system and has been shown to be active in yeast, animals and plant $^{5-9}$. It maintains proteostasis as a protein quality control mechanism by removing cleaved, damaged or misfolded proteins from the cell ${ }^{7,10,11}$. N-degrons comprise several determinants to target a substrate to the $\mathrm{N}$-end rule pathway. First, they must contain a destabilizing N-terminal amino acid that can be recognized by $\mathrm{N}$-end rule pathway-specific E3 Ub ligases (N-recognins). Second, another crucial factor is a certain flexibility and accessibility of the N-terminal amino acid enabling a proper recognition of the substrate ${ }^{12}$. Third, substrates need to contain at least one internal Lys in appropriate distance to the $\mathrm{N}$ terminus, which may serve as polyubiquitination site ${ }^{3}$. The $\mathrm{N}$-end rule pathway targets both cytosolic and nuclear substrates but also proteins localized in the membrane ${ }^{13}$.

Conditional protein expression via heat-sensitive $\mathrm{N}$-degrons was designed as a genetic tool to generate conditional, temperature-inducible alleles in budding yeast ${ }^{1}$. The system is based on rapid, reversible depletion or accumulation of POIs and targets the entire protein for proteasome-dependent proteolysis at a restrictive temperature. Therefore, it can be used as a rapid ON/OFF system for reversible accumulation of active proteins (Fig. 1a,b and Supplementary Fig. 1). Here an N-degron serves as a destabilizing N-terminal tag $(26 \mathrm{kDa})$ fused to the POI as a portable td cassette. It consists of three vital parts: (1) Ub that is co-translationally removed from the fusion by deubiquitinating enzymes (Ub-fusion technique ${ }^{14}$ ); (2) a thermo-labile mouse dihydrofolate reductase $\left(D H F R^{t s}\right)$ that triggers protein degradation at the restrictive (high) temperature; and (3) a destabilizing $\mathrm{N}$-terminal residue at the $U b-D H F R^{t s}$ junction, which is exposed after deubiquitination of the full fusion construct, which serves as dormant $\mathrm{N}$-degron and can be recognized by N-end rule E3 Ub ligases (Supplementary Fig. 1).

Even if a potential degron (that is, a motif theoretically recognized by a N-end rule pathway E3 Ub ligase) is present on the surface of a target, its conformational rigidity may prevent its recognition due to steric hindrance. A conformationally destabilized protein may contain formerly buried (cryptic) surface degrons (that is, dormant degrons), which were masked in a stabilized version of the protein ${ }^{15}$. In the classical yeast td degron, both happens according to the presented model ${ }^{1}$ : a previously rigid surface degron (N-terminal) undergoes conformational relaxation and previously buried degrons, such as internal Lys side chains, are exposed.

However, to date, this system has only been used at the singlecell level in yeast and cell culture where it requires restrictive temperatures of 37 or $42^{\circ} \mathrm{C}$ (refs 1,16,17). These high temperatures are beyond the physiological range of many multicellular organisms, including animals and plants ${ }^{18}$. Although there are alternative methods for conditional protein shut-off via degradation, for example, the protease-mediated TIPI ${ }^{19}$, the destabilizing domain (DD) systems ${ }^{20}$ and the auxininducible degron (AID) $)^{21}$, their use is also limited to cells in culture $^{22}$. The latter two systems require the addition of exogenous compounds to trigger the response (Supplementary Note 1).

To fill the gap of a conditional protein accumulation system for multicellular systems under physiological conditions, we constructed a low-temperature (lt) $\mathrm{N}$-degron and show its general applicability by studying seven POIs in five different model systems (that is, two plant species (Arabidopsis thaliana and Nicotiana benthamiana (tobacco)), Drosophila melanogaster (fruit fly), Drosophila cell culture and Saccharomyces cerevisiae (budding yeast). The design of the lt-degron not only allowed in vivo inactivation and depletion of proteins and enzymes but also tuning of protein levels and enzyme activity. Depending on the POI, we demonstrated triggering of developmental processes on demand. We define the temporal requirement of a transcriptional regulator protein mandatory for the formation of trichomes, which belong to the prime model cells in plant developmental genetics. Moreover, we made use of a developmental switch by stabilizing a transcription factor causing flowering on demand, triggered protein accumulation in $N$. benthamiana (tobacco), conditionally depleted proteins in cell culture and Drosophila flies. Therefore, the link to in-depth applications in developmental studies is addressed as well as the proof of concept for applications of the lt-degron in biotechnologically relevant contexts.

\section{Results}

$\mathrm{N}$-degron functionality in multicellular organisms. To assess $\mathrm{N}$-degron functionality in multicellular organisms, we chose easily scorable, quantitative and irreversible biological read-outs after temperature shifts in vivo, like the development of Arabidopsis trichomes (leaf hairs) and flower induction. We first asked whether the established yeast td degron containing the single-mutated $D H F R^{P 67 L}$ (termed ' $K 1^{\prime}$ '), exhibiting a restrictive temperature of $37-42^{\circ} \mathrm{C}$ (refs $\left.1,16,17,23\right)$ is functional in plants. Our DHFR was initiated by phenylalanine (Phe), a strongly destabilizing residue in plants, which is presumably recognized by the bona fide $\mathrm{N}$-end rule E3 Ub ligase PROTEOLYSIS1 (PRT1 $)^{24-26}$. As the first test system, we used the formation of Arabidopsis trichomes, which are a well-established model in cell and developmental biology ${ }^{27-29}$, and an attractive target for plant metabolic engineering. ${ }^{30} \mathrm{WD} 40$ protein TRANSPARENT TESTA GLABRA1 (TTG1) is an essential regulator for trichome development ${ }^{31}$, ttg1 mutants are devoid of trichomes (Figs 1c and 2a) but the mutant phenotype can be rescued by expressing TTG1 under control of the constitutive cauliflower mosaic virus $(\mathrm{CaMV}) 35 \mathrm{~S}$ promoter (Pro35S) $)^{32}$. In this evaluation system, the read-out for a functional $\mathrm{N}$-degron is the number of trichomes formed per leaf after the shift from permissive to restrictive temperature. Under permissive conditions, the degron is nonfunctional, that is, the POI will accumulate and form trichomes, whereas under restrictive conditions, the degron is active and leads to the degradation of the fusion protein, and leaves will be devoid of trichomes.

To this end, transgenic ttg1 mutant Arabidopsis plants were generated that expressed TTG1 fused to degron cassette K1 (Supplementary Fig. 2). We set the presumptive maximal restrictive temperature treatment to $29^{\circ} \mathrm{C}$, which is near but not above the upper end of the physiological temperature range of 
a

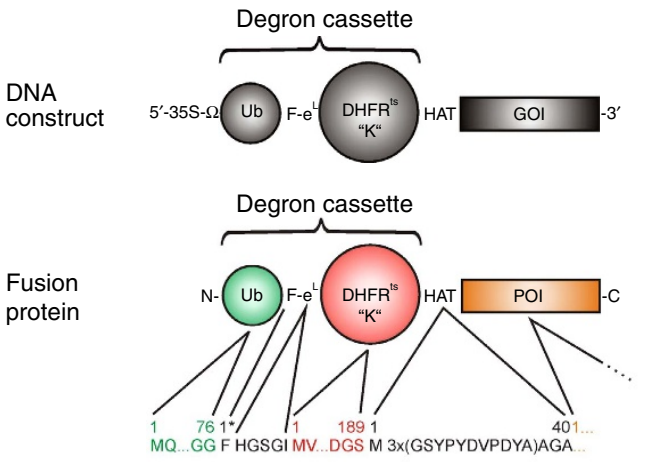

b

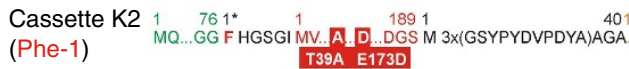

d

ttg1 Pro35S::K2:TTG1

$13^{\circ} \mathrm{C} \quad 29^{\circ} \mathrm{C}$

$t \quad 0 \longdiv { 1 0 3 0 6 0 9 0 } \overline { 2 . 5 3 . 5 4 . 5 \quad 2 4 }$

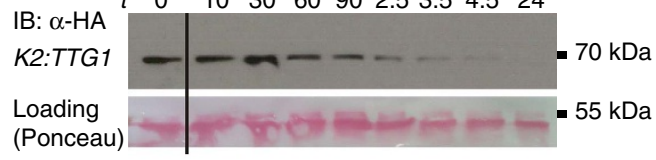

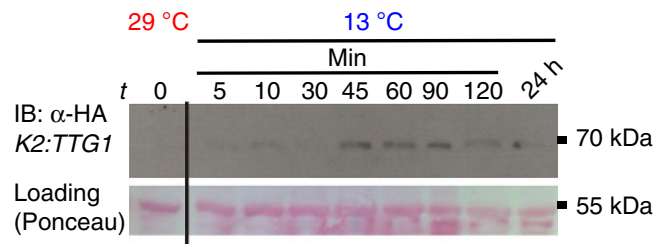

f

ttg1 Pro35S::K2:TTG1

$\frac{\text { prt1 }}{{ }^{\circ} \mathrm{O} O \mathrm{CO}} \frac{\mathrm{WT}}{\mathrm{OO} . \mathrm{C}}$

IB: $\alpha-\mathrm{HA}$

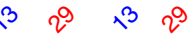

K2:TTG1

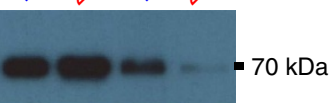

Loading

(CBB)

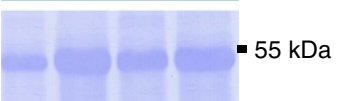

C

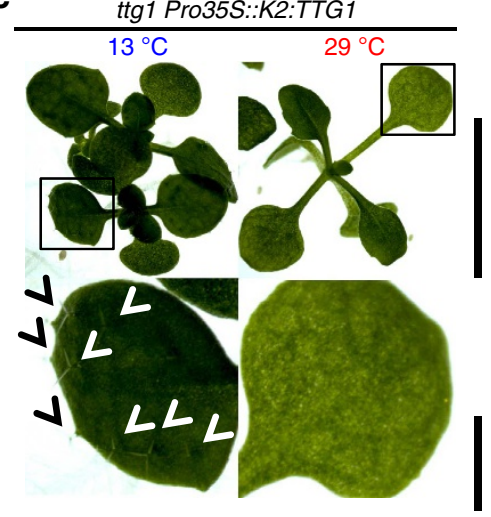

e

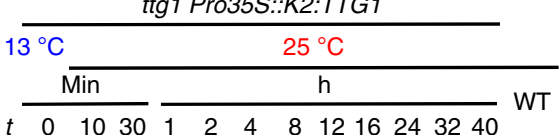

IB: $\alpha-\mathrm{HA}$

K2:TTG1

Loading

(Ponceau)
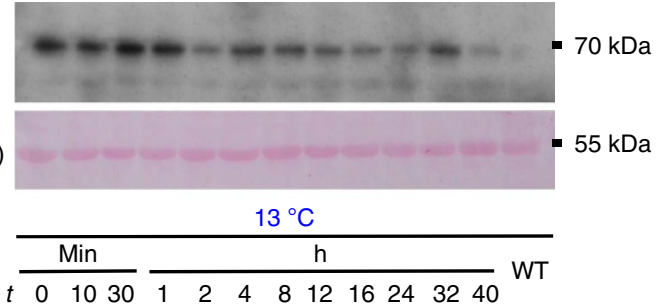

IB: $\alpha-\mathrm{HA}$

K2:TTG1

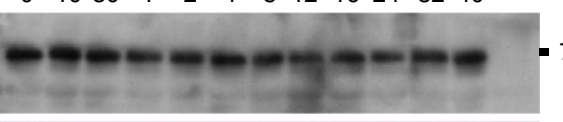

$70 \mathrm{kDa}$

Loading

(Ponceau)

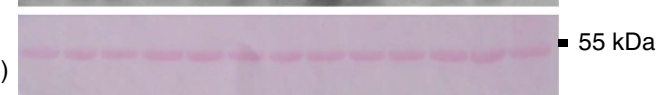

Figure 1 | Conditional protein depletion/accumulation cause developmental phenotypes on demand in vivo and can be used to develop trichome cells. $(\mathbf{a}, \mathbf{b})$ Lt-degron architecture. The mechanism of conditional N-degron containing protein depletion is shown in Supplementary Fig. 1, degron construct design is shown in Supplementary Fig. 2. (c) ttg1 K2:TTG1 plants grown at permissive or restrictive temperatures. Arrow heads indicate trichomes in inlets. Scale bar, $1 \mathrm{~cm}, 5 \mathrm{~mm}$ (inlet). (d) In vivo protein depletion time course of K2:TTG1 from transgenic ttg1 Pro35S::K2:TTG1 mutant plants. (e) In vivo dimming of K2:TTG1 levels by application of semi-permissive temperatures. Plants were subjected to temperature-shift experiments from 13 to $25^{\circ} \mathrm{C}$. Western blots of plants shifted to semi-restrictive $\left(25^{\circ} \mathrm{C}\right)$ and kept at constitutively permissive temperature $\left(13^{\circ} \mathrm{C}\right)$ are shown. Plants were shifted at $t=0$ from 13 to $25^{\circ} \mathrm{C}$ (upper panel) or kept at $13^{\circ} \mathrm{C}$ (lower panel). (f) Stabilization of K2:TTG in prt1. The K2:TTG fusion protein stabilizes in the prt1 mutant background under restrictive temperature indicating that the E3 ligase PRT1 is the principal component responsible for K2 degradation. K2:TTG also partially accumulates under permissive temperatures in the prt1 mutant background compared with the WT indicating that also here, the fusion protein is not fully stabilized. All samples derived from the same experiment, processed in parallel and leaves of the same developmental stage were compared. Data were confirmed by analysis of at least three biological replicates. Equal loading was further confirmed by Ponceau S staining of blotted and immunostained membranes.

Arabidopsis ${ }^{18}$ and found that K1:TTG1 stably transformed plants developed trichomes also at this temperature indicating that the fusion protein is not sufficiently destabilized (Supplementary Table 1).

To lower the restrictive temperature, we generated an N-degron variant containing a triple mutated $D H F R^{T 39 A / P 67 L / E 173 D}$ (K3) with two additional substitutions (T39A/E173D). We had previously identified the latter mutations in a yeast mutagenesis screen for destabilizing point mutations within DHFR (Supplementary Note 2$)^{33}$. However, ttg1 mutants containing K3:TTG1 never formed trichomes under any tested conditions. The protein appeared to be unstable after growing the plants at constitutively permissive or restrictive temperatures or shifting them between the two conditions (Supplementary Fig. 3 and Supplementary Table 1). Lack of trichomes under low temperatures correlated with levels of K3:TTG1 protein undetectable by western blot 
a

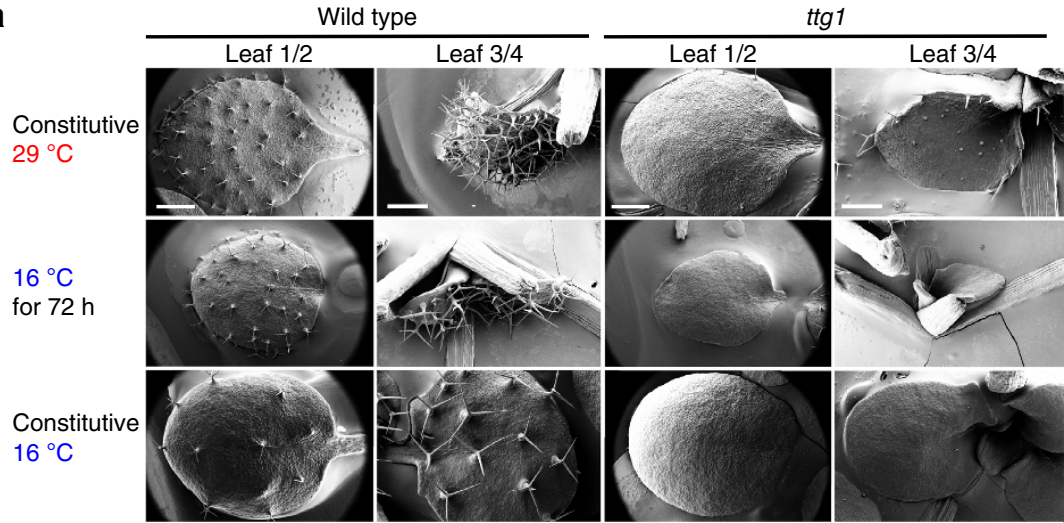

b

ttg1 Pro35S::K2:TTG1

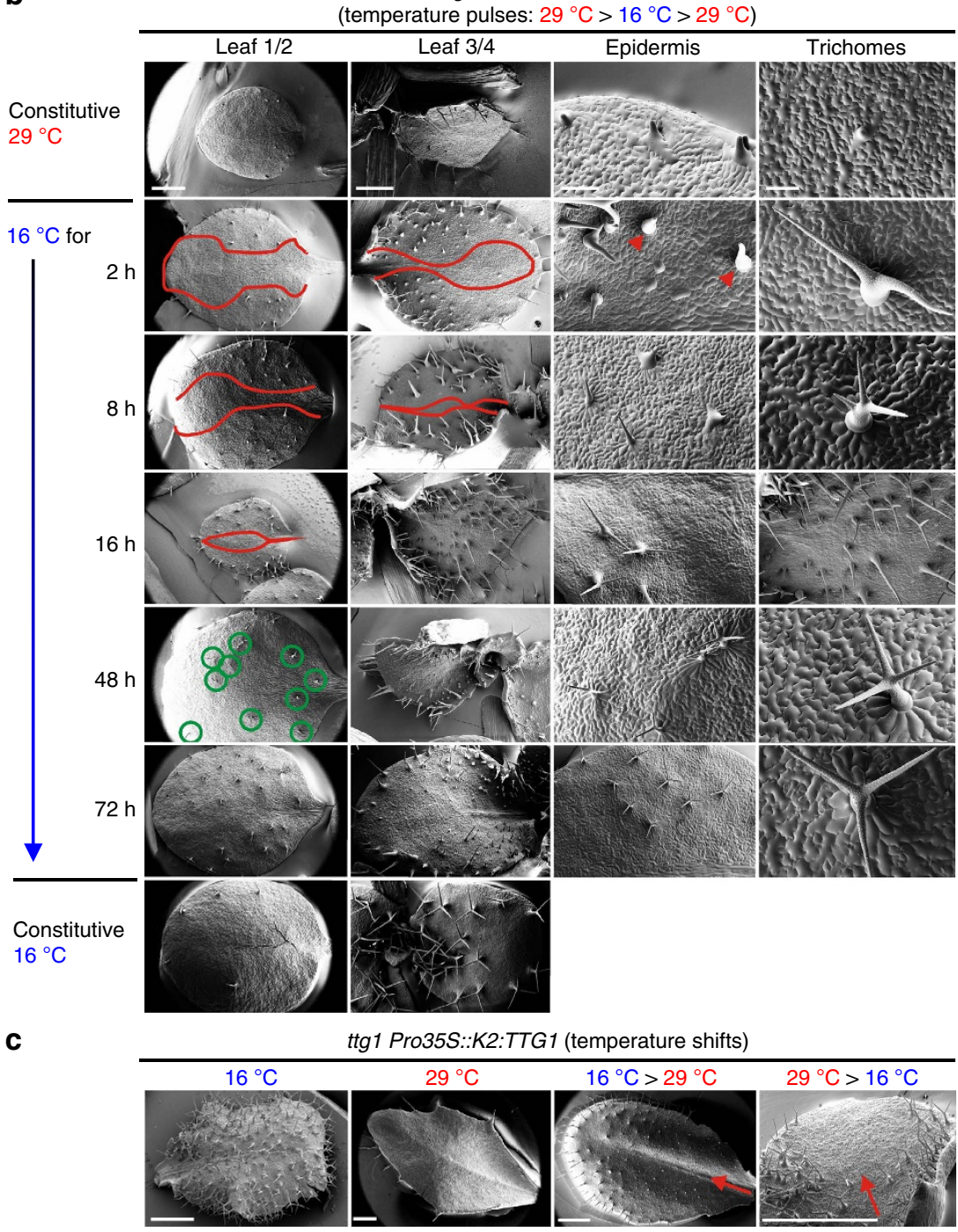

Figure 2 | Spatiotemporal development of trichomes as test system for conditional protein accumulation. (a) Phenotype of ttg1 mutants compared with the WT. Cryo scanning electron micrographs were taken from 4-week-old plants grown constitutively at 29 or $16^{\circ} \mathrm{C}$. Scale bar, $1 \mathrm{~mm}$. (b,c) Conditional complementation of ttg1 with K2:TTG1 depending on temperature and time. SEMs of 4-week-old ttg1 K2:TTG1 plants. (b) Temperature-pulsing of K2:TTG1 protein in $t \operatorname{tg} 1$ by short shifts from the restrictive to the permissive temperature $\left(16^{\circ} \mathrm{C}\right)$. Control plants were grown constitutively at restrictive $\left(29^{\circ} \mathrm{C}\right.$, upper row) or permissive $\left(16^{\circ} \mathrm{C}\right.$, bottom row) temperatures. Centre: plants grown at restrictive and shifted to permissive temperature for the time indicated $(2-48 \mathrm{~h})$. Red lines: borders of trichome initiation zone moving from lateral to medial with duration of the K2:TTG1 pulse. Green circles: fully mature trichomes and epidermal patterning appearing after $48 \mathrm{~h}$. Arrow heads: loped circumference at trichome bases. Scale bars, $1 \mathrm{~mm}$ (left), $500 \mu \mathrm{m}$ (second and third columns) and $100 \mu \mathrm{m}$ (right). (c) WT- and ttg1-like glabrous leaves of ttg1 K2:TTG1 grown at permissive and restrictive temperatures (left two panels) or after temperature up- and downshifts during leaf development (right two panels). Arrows: direction of proximo-distal leaf development highlighting the sector affected by the temperature shift. A phenotypic comparison of different degron variants is shown in Supplementary Fig. 3, expression levels of all degron fusion genes under restrictive and permissive conditions are presented in Supplementary Fig. 4. Molecular dynamics simulations and models of the DHFR variants used are presented in Supplementary Fig. 5. 
analysis although its transcript was found (Supplementary Fig. 3). These findings indicated that proteins carrying the $K 3$ degron are too unstable at lower temperatures to provide a permissive phenotype.

Novel it N-degron for in vivo application. Finally, we fused TTG1 to DHFR ${ }^{T 39 A / E 173 D}(K 2)$, which only contains the two destabilizing point mutations $T 39 A / E 173 D$ identified in the mutagenesis screen. The expression of K2:TTG1 caused a conditional (that is, temperature-dependent) restoration of trichomes in the ttg1 mutant background (Figs 1c and 2b,c, Supplementary Fig. 3 and Supplementary Table 1). In time-course experiments, decreasing and increasing levels of K2:TTG1 protein could be tracked as a consequence of temperature up- or downshifts causing depletion versus accumulation (Fig. 1d). Neither the endogenous TTG1 protein without the lt-degron nor the K2:TTG1 transcript levels responded to the temperature shifts when tested in a transgenic ttg1 TTG1-HA complementation line (Supplementary Figs 3a and 4a).

For the classical temperature-induced yeast $\mathrm{N}$-degron, it was hypothesized that after heat-induction, a dormant $\mathrm{N}$-terminal degron becomes active after conformational changes and that internal Lys side chains get exposed ${ }^{1}$. We tested this hypothesis for the point mutations present in the sequences of the DHFR variants of the classical td (K1) and our novel lt-degron (K2) by stability predictions and molecular dynamics simulations (Supplementary Table 2 and Supplementary Note 3). Modelling of the point mutations within the DHFR crystal structure suggested that $E 173 D$ contributes to a higher conformational flexibility and increases the exposure of Lys side chains on the surface under elevated temperatures. This may lead to a better accessibility to the ubiquitination machinery (Supplementary Fig. 5a-d).

$\mathrm{N}$-terminal accessibility and $\mathrm{N}$-end rule requirements. We hypothesized that a possible hyper-destabilization of K3:TTG1 could be due to the flexibility introduced by the short linker $\mathrm{e}^{\mathrm{L}}$ (2-His-Gly-Ser-Gly-Ile-6; Supplementary Figs 2,3) between DHFR and the destabilizing Phe residue compared with the classical yeast degron ${ }^{34}$. By deleting $\mathrm{e}^{\mathrm{L}}$ from the degron cassettes and thus making the destabilizing $\mathrm{N}$-terminal Phe less accessible for the $\mathrm{N}$-end rule Ub ligases, we tested if a conditional phenotype can now be observed as a way to further optimize, that is, decrease, the restrictive temperature of the system. However, transgenic plants expressing K3:TTG1 lacking $\mathrm{e}^{\mathrm{L}}$ showed very similar phenotypes as the previously tested $\mathrm{e}^{\mathrm{L}}$-containing versions. Similarly, only expression of $\mathrm{K} 2: \mathrm{CO}$ containing the linker led to a temperature-dependent response, the constructs lacking the linker did not (Supplementary Table 1 and Supplementary Fig. 3).

As control, cassette $K 4$ was engineered. It contains the same DHFR variant as $K 2$ but starts with a methionine and can therefore not be recognized by $\mathrm{N}$-end rule $\mathrm{E} 3$ ligases due to the lacking destabilizing N-terminal residue (Supplementary Figs 2 and 3). The T39A and E173D mutations were previously shown to cause degradation by a protein quality control pathway at higher temperatures $\left(30^{\circ} \mathrm{C}\right)^{33}$. The K4:TTG1 phenotypes were highly variable but not temperature-dependent as expected from a conditionally stable TTG1-td (Supplementary Fig. 3c,d and Supplementary Table 1). K4:TTG1 plants developed trichomes regardless of the growth temperature. These data demonstrated that the destabilizing $\mathrm{N}$-terminal Phe residue is a critical feature of the conditional lt $K 2$ degron.

Tuning of protein levels. Indeed, protein accumulation by this novel lt-degron containing the $K 2$ cassette was even tuneable and allowed fading out the POI to achieve intermediate levels at semi-restrictive temperatures (Fig. 1e). For this experiment, plants were shifted at $t=0$ from 13 to $25^{\circ} \mathrm{C}$ or kept at $13^{\circ} \mathrm{C}$. Protein degradation appeared slower when shifted to $25^{\circ} \mathrm{C}$ compared with restrictive temperature (Fig. 1d), and low levels of POI were still detectable after $40 \mathrm{~h}$. The decrease of lt-protein over time could be observed reaching a level lower than at permissive but higher than at restrictive temperatures. To test for the requirement of a functional $\mathrm{N}$-end rule pathway in the host organism to efficiently degrade the Phe-initiated lt-degron, we introgressed $\operatorname{ttg1}$ K2:TTG into the prt1 mutant. Proteins with initiating Phe at their $\mathrm{N}$ terminus are expected to be recognized by one of the two known plant N-recognins, namely PRT1. We observed that the fusion protein is stabile in the prt1 mutant background also at restrictive temperature (Fig. 1f).

Triggering trichome induction on demand. The tunability of K2:TTG1 and the conditional induction of trichomes in the mutant background allowed us to perform previously impossible experiments, that is, to dissect the temporal requirement of TTG1 function during trichome establishment and maturation in great detail (Fig. 2b,c). Taking the pattern of wild-type (WT) trichome distribution into account ${ }^{35}$, we found that a pulse of K2:TTG1 protein is needed for at least $2 \mathrm{~h}$ to establish a trichome fate during the initial induction phase (Fig. $2 \mathrm{~b}, \mathrm{c}$ ). After a pulse of $2 \mathrm{~h}$ at permissive temperature of $16^{\circ} \mathrm{C}$, the front of the trichome initiation sites started to move proximal to the midvein and trichomes began to differentiate (branching). Notably, initiation sites develop proximal to the mid-vein as spots with enlarged precursor cells, suggesting that different leaf areas have a differential predisposition to form trichomes. After $8 \mathrm{~h}$, further branch points are formed and few three-branched, albeit not fully developed, trichomes appeared. Many trichomes formed a loped circumference, which is typical for de-differentiation if initial maintenance of cell fate is not completed ${ }^{36}$. After $16 \mathrm{~h}$, a spacing pattern was formed indicating robust trichome maintenance. Forty-eight hours of TTG1 function were needed for developing WT-like three-branched trichomes. Expansion and partial restoration of a WT-like distribution pattern, as well as morphology of trichomes, is fully accomplished after $72 \mathrm{~h}$ of TTG1 action (Fig. 2b). Here the lt-degron allowed us to determine the temporal requirement of TTG1 in the context of the development of a highly specific cell type.

Switching floral induction on demand. As a second test system with an easily scorable biological read-out, we chose WT Arabidopsis plants that conditionally overexpress the transcription factor CONSTANS (CO), a key regulator of flowering time ${ }^{37}$. Overexpressing $C O$ causes a rapid shift from the vegetative to reproductive growth mode and thereby an early flowering ${ }^{38,39}$. Thus, at permissive temperatures, plants expressing a functional degron-CO fusion protein (CO-td) were expected to flower earlier than plants grown under the restrictive temperature. The read-out is hence the days till flowering at permissive temperature in comparison with the WT. Similarly to the TTG1-td constructs, neither K1:CO nor K3:CO showed a temperature-dependent phenotype (Supplementary Table 1). In contrast, the lt-degron system very efficiently worked as expression of $\mathrm{K2}: \mathrm{CO}$ at the permissive temperature caused early floral induction. Here the inducible formation of flower meristems occurred about 14 days earlier than in the WT when grown at the same permissive temperature (Fig. 3a). No differences were found when plants were grown at the restrictive temperature as in a time-course experiment, the onset of flowering was observed from day 15 onwards for both WT and K2:CO plants (Supplementary Fig. 6). 
a

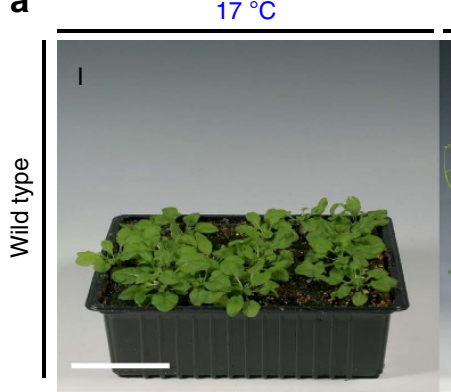

$17^{\circ} \mathrm{C}$

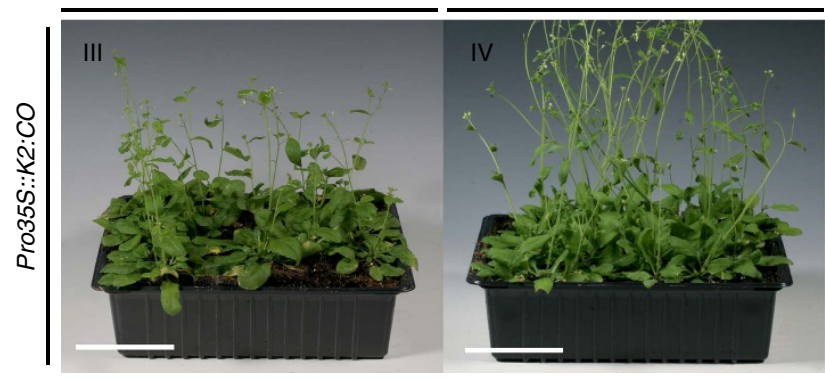

b

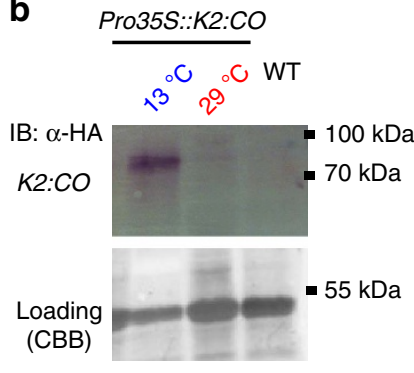

C

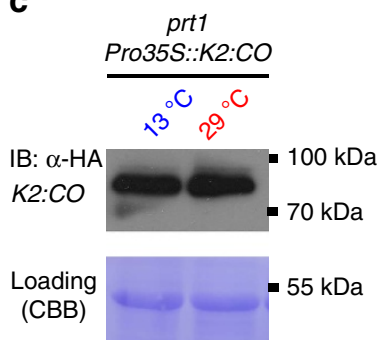

Figure 3 | Switchable flower meristems by conditional accumulation of CO-td. (a) Conditional expression of CO-td fusion leads to premature flowering in vivo. Four-week-old (I and II) WT and (III and IV) K2:CO transgenic plants grown under permissive and restrictive temperatures and short-day conditions. (III) In transgenic K2:CO plants, plants bolted earlier than in the WT (I). Scale bars, $5 \mathrm{~cm}$. (b) K2:CO protein levels from transgenic plants grown at permissive or restrictive temperature. (c) Stabilization of $\mathrm{K} 2 \mathrm{CO}$ in prt1. The $\mathrm{K2:CO}$ fusion protein stabilizes in the prt1 mutant background under restrictive temperature indicating that the E3 ligase PRT1 is required for K2 degradation. For details on N-degron technology, see Supplementary Fig. 1; for construct layout, see Supplementary Fig. 2. For transcript levels under restrictive and permissive conditions, see Supplementary Fig. 4. A developmental time-course experiment for CO-td is shown in Supplementary Fig. 6.

This phenotype correlates with decreased levels of $\mathrm{K} 2: \mathrm{CO}$ under restrictive conditions while transcript levels remained unchanged (Fig. 3b and Supplementary Fig. 4b). K2:CO introgressed into prt1 lead to stabilization of the fusion protein also at restrictive temperature (Fig. 3c). Here conditionally stable CO-td, enabled us to control the onset of flowering and to generate floral meristem cells, that is, specialized cell types, on demand.

In vivo inactivation and depletion of proteins and enzymes. To further assess the application spectrum of the lt-degron in plants, we chose green fluorescent protein (GFP), $\beta$-glucuronidase (GUS) and tobacco etch virus protease (TEV) as additional target proteins to be tested when stably transformed in Arabidopsis. K2:GFP robustly followed the accumulation/depletion regime (Fig. 4a,b and Supplementary Fig. 4c). Moreover, for K2:GFP, we have designed two different lt-degron cassettes to test for degradation via two known branches of the $\mathrm{N}$-end rule pathway. We used either the previously mentioned Phe or, as another potentially destabilizing residue, Arg, which results as neo-Nterminal after deubiquitination of the translated K2:GFP fusion protein. These residues are expected to be recognized by the two known N-recognins, that is, Arg via PRT6 and Phe via PRT1. The response of these two constructs was compared under standard growth conditions (Supplementary Fig. 4c) and in time-course experiments (Supplementary Fig. 4d) to demonstrate robustness. Both destabilizing $\mathrm{N}$ termini gave comparable, strongly temperature-dependent results and revealed that the lt-degron is functional by both branches of the $\mathrm{N}$-end rule pathway.

Histological staining for K2:GUS revealed activity of the fusion protein in vivo at permissive and a significantly reduced activity at restrictive temperature (Fig. 4c). K2:GUS protein levels and activity were strongly decreased for individuals grown constitutively at restrictive temperature (Fig. 4 d,e) with transcript levels unchanged (Supplementary Fig. 4e). In time-course experiments,
K2:GUS protein levels increased and correlated with high enzyme activity after shift to permissive temperature and vice versa if shifted to restrictive conditions (Fig. 4f,g). K2:GUS western blots showed two bands of different sizes (Fig. 4d,f). To identify the K2:GUS population with a temperature-dependent hydrolase activity, which accumulates at permissive temperature, we analysed the bands by mass spectrometry (Supplementary Fig. 7). This revealed that only the K2:GUS population, which accumulated at the permissive temperature contains the lt-degron part and is highly active (Fig. 4e,g). At the same time, K2:GUS is stabilized also at restrictive temperature after the addition of proteasome inhibitor indicating the degradation of the fusion protein via the Ub/proteasome system (Supplementary Fig. 4f).

Tuning of activity levels. To further strengthen our claim on the temperature-dependent tunability of the lt-degron system, we performed temperature-shift assays with ProUBQ10::K2:GUS addressing temperature-dependent changes in both protein and activity levels at various temperatures (Fig. $4 \mathrm{~h}$ ). In contrast to the in vivo dimming of K2:TTG1 (Fig. 1e), this represents a more appropriate tuning experiment because here, the activity of the conditional lt-POI could be quantified in relation to the lt-POI protein levels and total protein content of the sample. The levels of active K2:GUS fusion protein were stabilized and its activity, as monitored by the quantitative GUS assay, followed the increased or decreased protein levels according to the applied temperatures in the permissive to restrictive range. Moreover, K2:GUS activity levels can be efficiently regulated by means of different temperatures. All of this indicated a high flexibility of the lt-degron regardless of temperature adjustment from permissive to restrictive temperature or vice versa.

Application of lt-degrons in $\mathbf{N}$. benthamiana. Next, we applied our low-temperature approach to TEV as a target, which is widely 

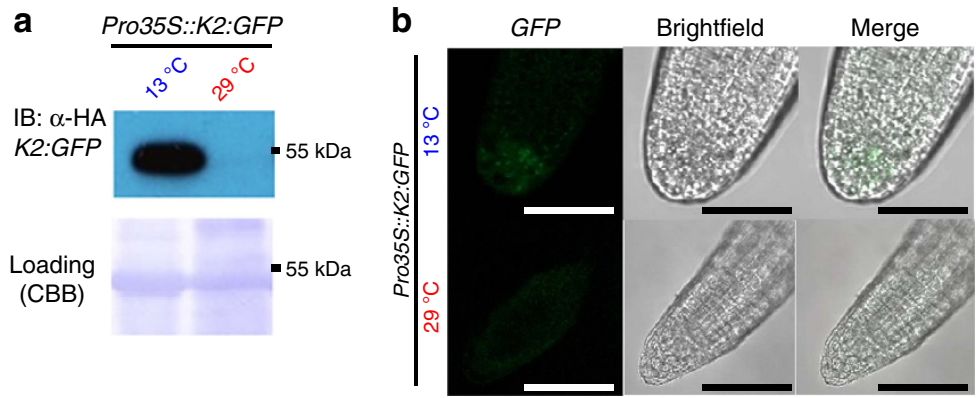

C
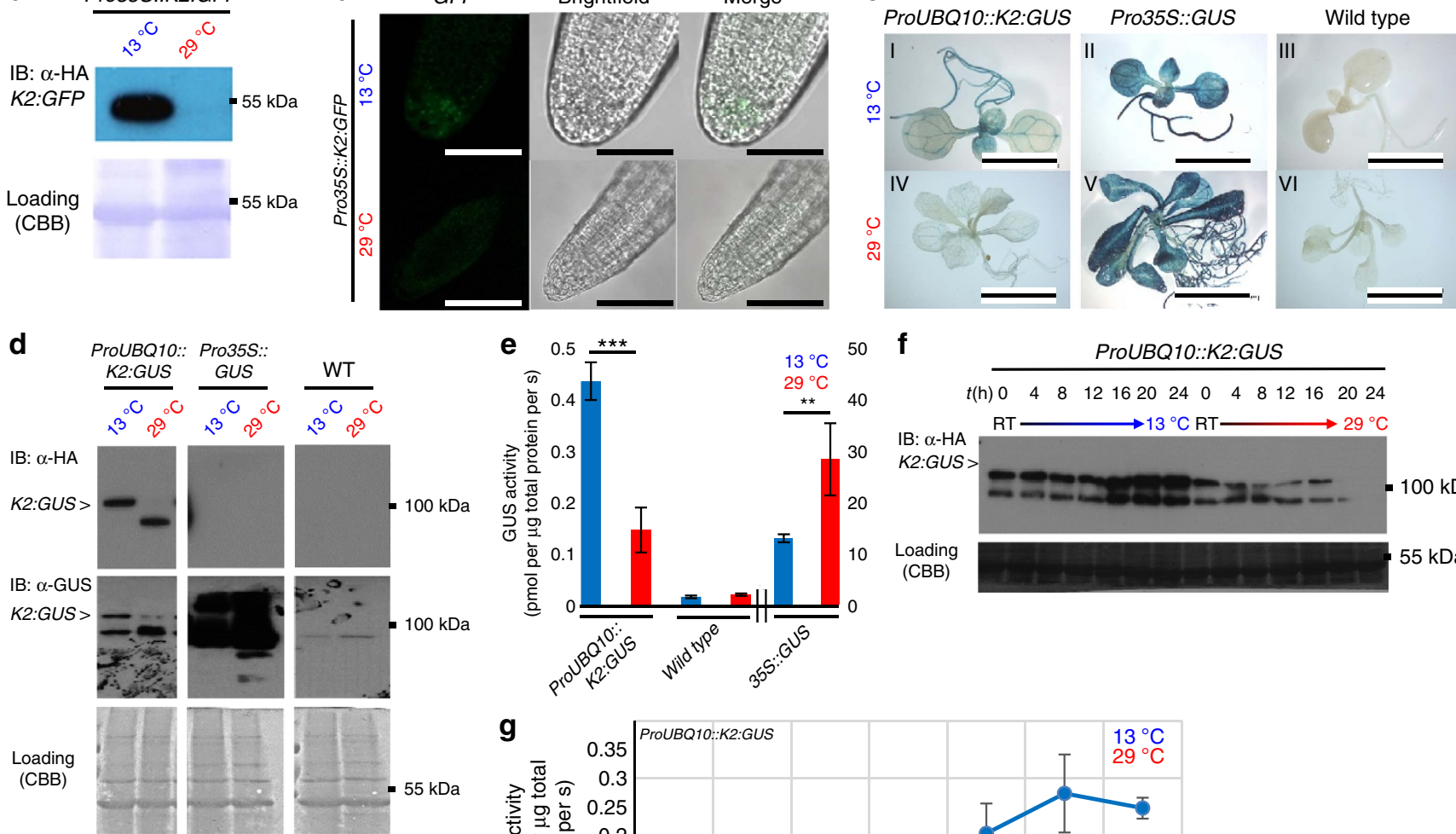

f
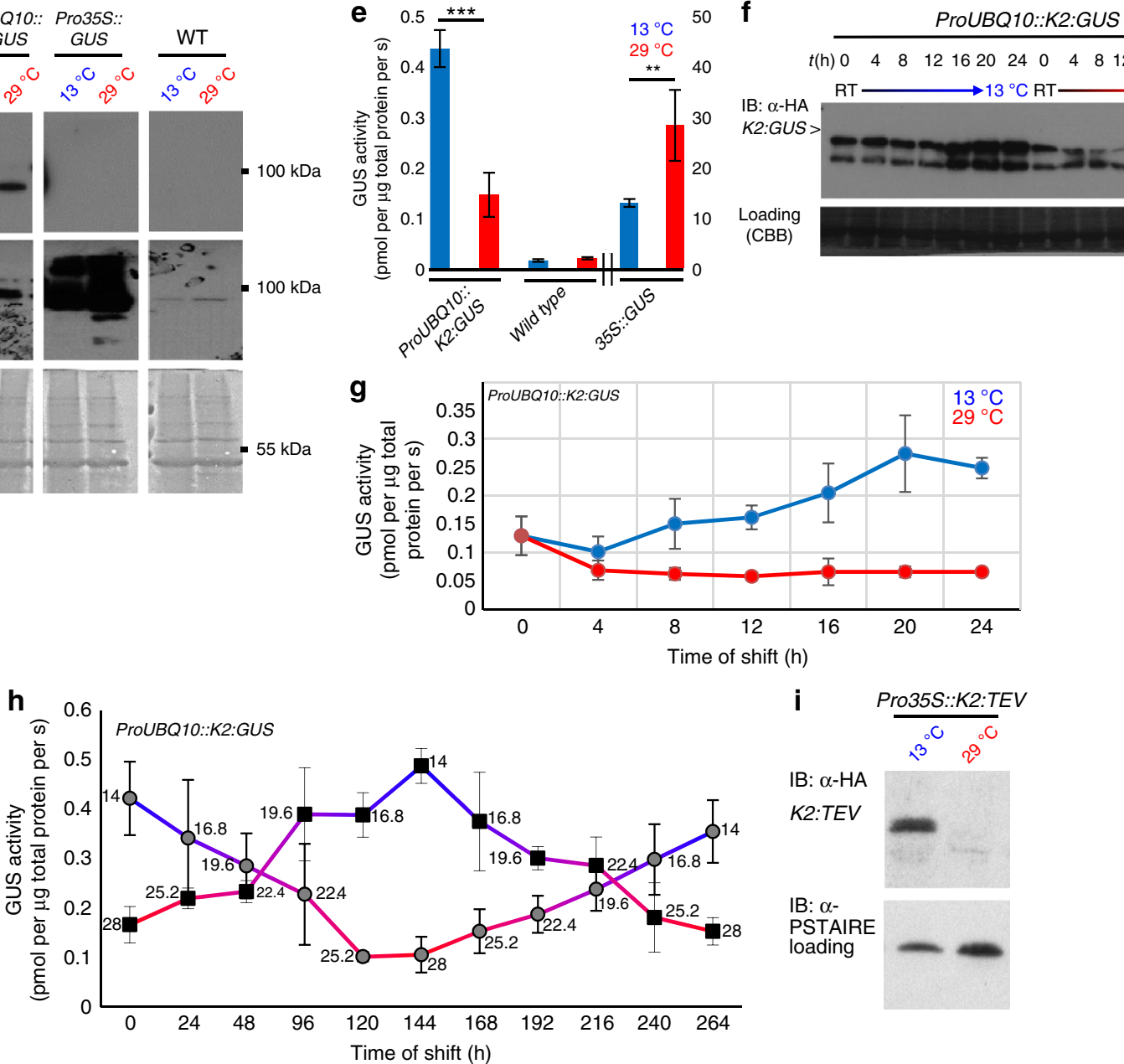

Figure 4 | Conditional molecular phenotypes are linked with protein degradation and deactivation of It-degron fusion proteins. (a) Conditional accumulation of K2:GFP fusion protein in whole seedlings and (b) functionality of K2:GFP in root tips. Also Arg-initiated K2:GFP is conditionally depleted (Supplementary Fig. 4c). Scale bar, $50 \mu \mathrm{m}$. (c) In vivo hydrolase activity of transgenic ProUBQ10::K2:GUS compared with Pro35S::GUS, overexpression lines and the WT constitutively grown at permissive or restrictive temperature. Scale bar, $1 \mathrm{~cm}$. (d) $K 2: G U S$ protein levels of seedlings constitutively grown at the indicated temperatures. Membranes were immunostained with $\alpha$-HA antibody followed by a second staining with $\alpha$-GUS antibody after stripping. The asterisk indicates K2:GUS protein. (e) Quantitative GUS assays of plants constitutively grown at 13 versus $29^{\circ} \mathrm{C}$. Six biological replicates were performed for K2:GUS and three biological replicates for WT and 35S::GUS. All samples were measured as three technical replicates. $P$ values for Student's $t$-test (two-sided t-test, type 3) are K2:GUS: $\left.6.44766 \times 10^{-7}{ }^{(\star \star}\right)$; 35S::GUS: $\left.0.004365663{ }^{\star \star}\right)$. All error bars in this panel represent s.d., asterisk: significant. (f) Western blots of ProUBQ10::K2:GUS seedlings constitutively grown at ambient temperature (room temperature (RT)) shifted to permissive or restrictive temperature. (g) Quantitation of enzyme activity of $\mathbf{f}$. Seedlings were grown under standard long-day conditions $\left(16-\mathrm{h}\right.$ light, 8 -h dark, $\left.21^{\circ} \mathrm{C}\right)$ aseptically on MS plates. One-week-old seedlings were shifted to permissive or restrictive conditions, respectively. In all, 5-10 individual seedlings were collected and pooled every $4 \mathrm{~h}$. Three biological replicates were performed with two technical replicates each. All error bars in this panel represent s.d. (h) Degron tuning assay monitoring K2:GUS activity through temperature shift. Plants expressing ProUBQ10::K2:GUS were grown at cold (permissive) or warm (restrictive) temperature and then shifted to the respective opposite temperature and back over the course of 10 days. Samples were taken every $24 \mathrm{~h}$, followed by a temperature shift of $2.8^{\circ} \mathrm{C}$. Activity of the K2:GUS fusion protein clearly follows the temperature shift. The numbers next to the data points represent the sampling temperature, $n=3$. All error bars in this panel represent s.d. MS analysis of K2:GUS populations is documented in Supplementary Fig. 7 . (i) K2:TEV in stably transformed Arabidopsis plants. Western blot of material collected from seedlings grown at permissive and restrictive temperatures. Equal loading was further confirmed by staining of blotted membranes with Coomassie Brilliant Blue G225 after immunostaining or $\alpha$-PSTAIRE antibody detecting CYCLIN-DEPENDENT KINASE A;1 (CDKA;1). For transcript levels under restrictive and permissive conditions, see Supplementary Fig 4. 
used for cleaving proteins in vitro and in vivo. The protease can be expressed for site-specific protein cleavage in many different host organisms without causing adverse effects ${ }^{40}$. In Arabidopsis, K2:TEV transcript levels were unaffected by temperature shifts (Supplementary Fig. 4g), but the fusion protein accumulated exclusively at permissive temperature (Fig. 4i).

$N$. benthamiana (tobacco) plants are widely used expression hosts for plant-made pharmaceuticals and high-value proteins. Therefore, we tested the lt-degron in tobacco, which was transiently transformed with $K 2: T E V$. The fusion protein was depleted from plants shifted to $29^{\circ} \mathrm{C}$ and accumulated in individuals grown at $13{ }^{\circ} \mathrm{C}$ (Fig. 5a). A conditional TEV offers opportunities for downstream processing of recombinant proteins by intracellular cleavage. In addition to K2:TEV, K2:GUS and a fusion of $K 2$ with the agriculturally important herbicide resistance proteins phosphinothricin- $\mathrm{N}$-acetyltransferase (PAT) were also expressed in a conditional manner in tobacco (Fig. 5b,c). Together these findings established that the lt-degron approach was also suitable for the manipulation of tobacco and therefore is likely applicable for many more plant species.

Conditional protein depletion in S. cerevisiae. To test whether the lt-degron system is also functional outside of plant species, we used orotidine $5^{\prime}$-phosphate decarboxylase (URA3) as a reporter in $S$. cerevisiae. URA3 functionality and half-life were tested at 17.5 and $27^{\circ} \mathrm{C}$ in the WT, in $u b r 1-\Delta$ lacking the functional $\mathrm{N}$-end rule pathway E3 Ub ligase UBR1 and in $u m p 1-\Delta$, with impaired proteasome function (Fig. 6a). Experiments in WT (JD47-13C), $u b r 1-\Delta$ (JD55) and ump1- $\Delta$ (JD59) strains revealed that $K 1$ and $K 2$ confer uracil prototrophic growth in the ubr1- $\Delta$ and ump1- $\Delta$ mutants at all temperatures that were generally growthpermissive for these strains, and at lower temperatures in WT cells (Supplementary Fig. 2c). Increasing the temperature, however, resulted in growth inhibition of the WT strain expressing these constructs on media lacking uracil. Moreover, in WT cells, a strong decrease of fusion protein was observed $30 \mathrm{~min}$ following a shift to $27^{\circ} \mathrm{C}$ (Fig. 6b). Thus, the lt-degron allows a significantly lower restrictive temperature by about $10^{\circ} \mathrm{C}$ compared with the classical temperature-controlled $D H F R^{P 67 L}$ variant.

Conditional protein depletion in Drosophila. We then tested the lt-degron in D. melanogaster using K2:GFP and K2:TEV as model POIs. K2:GFP was destabilized after a shift from stabilizing 15 to $29^{\circ} \mathrm{C}$ in embryonic Kc cells subjected to a temperature shift for $4 \mathrm{~h}$ (Fig. 7a,b). K2:TEV was depleted from macrophage-like Schneider 2 (S2) cells after a shift from 16 to $29^{\circ} \mathrm{C}$ (Fig. 7c). A stable transgenic Drosophila line expressing K2:TEV under the control of the Actin5c promoter proved the principle in vivo. After shifting the living flies from the permissive $\left(18^{\circ} \mathrm{C}\right)$ to the restrictive $\left(29^{\circ} \mathrm{C}\right)$ temperature, we observed that K2:TEV becomes instable (Fig. $7 \mathrm{~d}$ ). This revealed that the lt-degron has a broad spectrum of applications and can be used to modulate protein abundance not only in plants and yeast but also in animal cell culture and living insects.

\section{Discussion}

Tight modulation of protein activities is still a major challenge, especially in multicellular organisms. We introduce here a transferable lt-degron for obtaining conditional mutants coupled to tunable protein accumulation in entire plants, insects and cell culture. The lt-system allows a rapid and reversible modulation of protein function and enzymatic activities. This was demonstrated in the case of seven different targets in five model systems, suggesting that it is generic and versatile.

Pronounced and unique technical advantages of the method over comparable systems include non-invasive functionality in a wide range of multicellular organisms, the lack of technically difficult or costly applications of exogenous chemical triggers, the possibility of the formation of cell and tissue types on demand by direct action on protein activity, and the perspective of applicability in large scale, for example, in entire growth containments, as the trigger is temperature.

In today's age of recent technological advances where sitespecific gene inactivation is becoming routine, clearly methods for the re-introduction of tightly and rapidly controllable conditional genes will allow additional functional analyses. In combination with CRISPR/Cas9, ZFNs or TALENs, our method allows directed generation of novel conditional alleles of genes, including essential ones, at the organismal and tissue-specific level. The lt-degron is technically well suited for the application in poikilothermal animals such as fishes, amphibians, reptiles, insects and other invertebrates, facilitating the design of conditional knockout animals in many model systems to dissect, for example, developmental programmes.

We recently discussed the classical heat-inducible $\mathrm{N}$-degron with other techniques for conditionally altering protein abundance and generating phenotypes on demand (Supplementary a
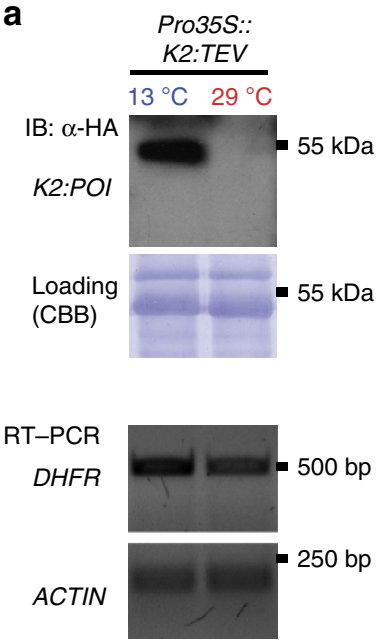

b
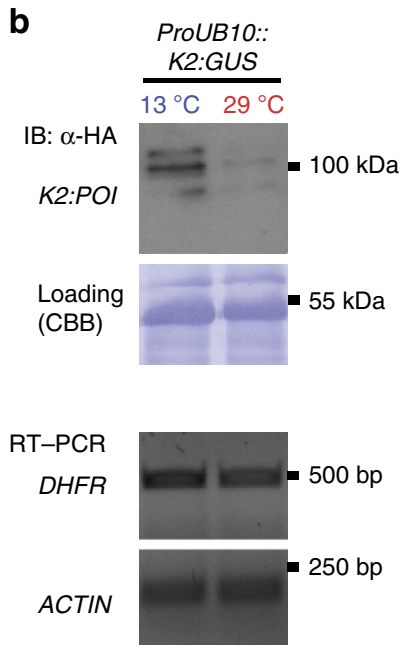
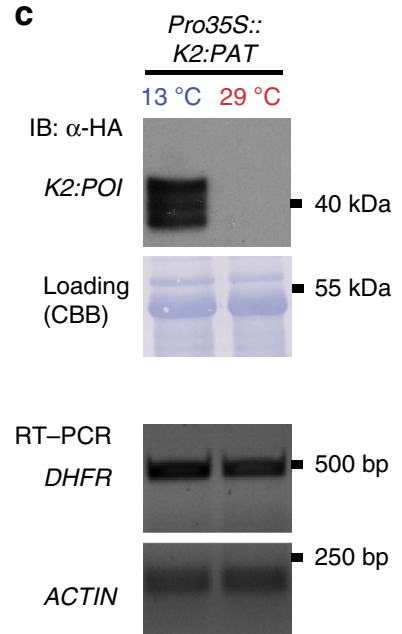

Figure $\mathbf{5}$ | The It-degron in $\mathbf{N}$. benthamiana as a protein accumulation system. (a) Stability and transcript levels of K2:TEV in transiently transformed $N$. benthamiana (tobacco) plants. (b) Conditional expression of K2:GUS and (c) of K2:PAT. Equal loading was confirmed by staining of blotted membranes with Coomassie Brilliant Blue G225 after immunostaining. 
Note 1$)^{22}$. In contrast, the system presented here is expected to work for many proteins under physiological conditions in multicellular, intact organisms, however, different aspects have to be taken into consideration when adopting this technique: (1) POIs must tolerate N-terminal fusions of about $26 \mathrm{kDa}$, a C-terminal fusion is not feasible; (2) POIs must at least a

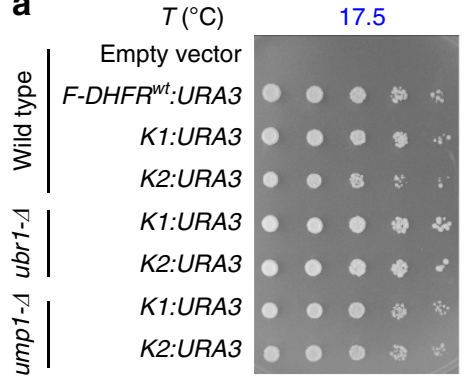

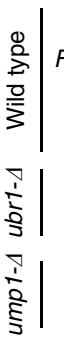

Empty vector

-DHFR ${ }^{\text {wt. }}$ URA3

K1:URA3

K2:URA3

K1:URA3

K2:URA3

K1:URA3

K2:URA3
27
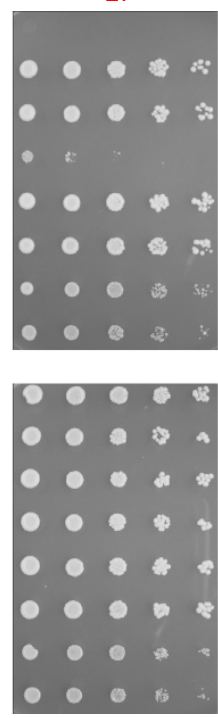

30
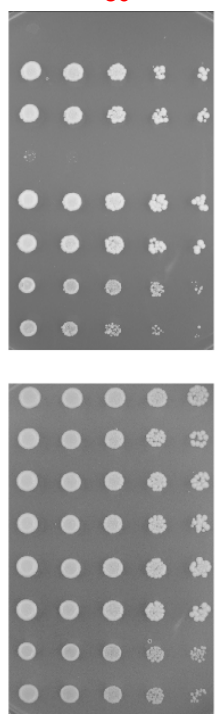

37
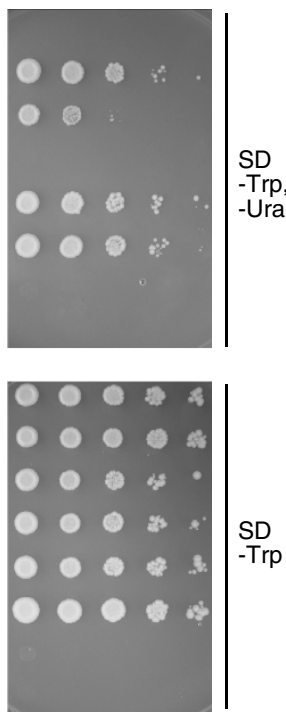

b

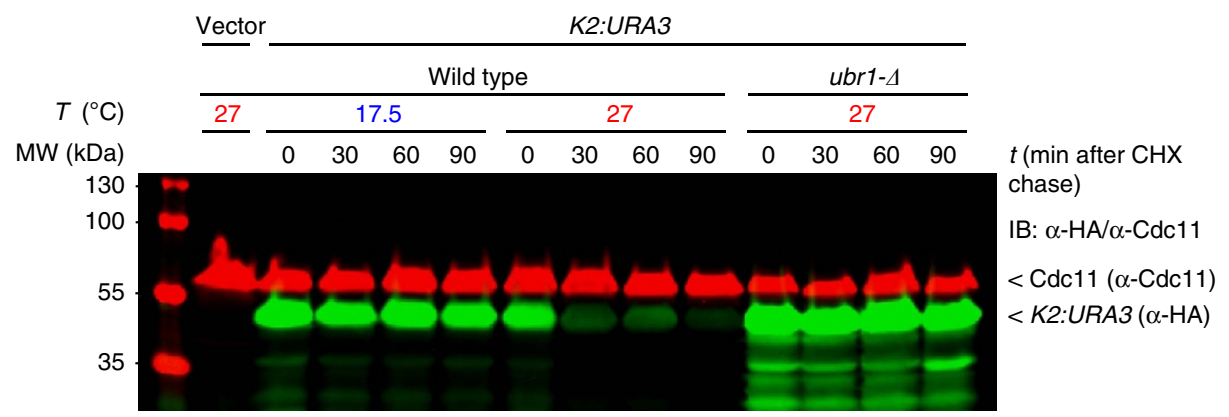

Figure 6 | The It-degron significantly lowers the restrictive temperature for conditional alleles in S. cerevisiae. (a,b) Modulation of enzyme activity and protein degradation in S. cerevisiae. Yeast cells were transformed with F-DHFR ${ }^{w t}: U R A 3$, K1:URA3, K2:URA3 under control of the copper-inducible $\mathrm{P}_{\text {CUP1 }}$ promoter. (a) Spot tests of WT, ubr1- $\Delta$ or ump1- $\Delta$ cells in serial (1:5) dilutions grown for 3 days at the indicated temperatures. Plates were grown at $17.5^{\circ} \mathrm{C}$ for 5 days. ump1- $\Delta$ shows a general growth defect at elevated temperature. (b) Cycloheximide (CHX) chase of K2:URA3. Equal loading was confirmed by simultaneously probing against Cdc11 (red signal).

a

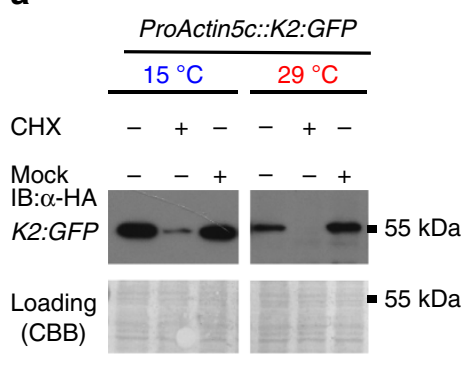

b

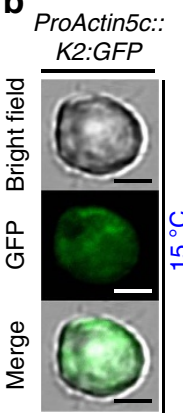

C

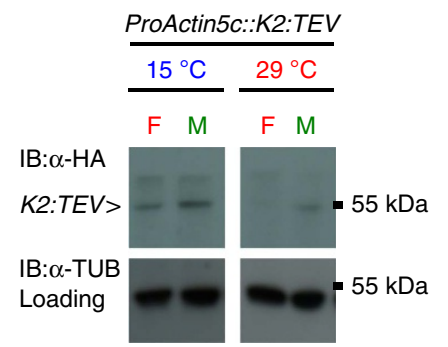

d

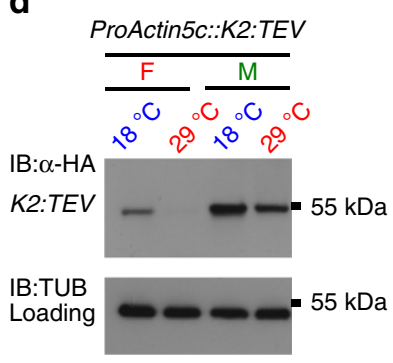

Figure 7 | Conditional protein depletion in cell culture and living Drosophila flies. (a-d) Modulation of protein abundance in $D$. melanogaster. Two of the most commonly used Drosophila cell lines, as well as stably transformed living flies were used as follows. (a) K2:GFP stability in embryonic Drosophila Kc cells with 24-h recovery after transfection and after a temperature shift for $4 \mathrm{~h}$ from permissive $\left(15^{\circ} \mathrm{C}\right)$ to restrictive temperature $\left(29^{\circ} \mathrm{C}\right)$. $\mathrm{CHX}$ chase was performed with $100 \mu \mathrm{g} \mathrm{ml}^{-1}$ in DMSO. (b) K2:GFP functionality detected as green fluorescence at permissive temperature. Scale bar, $2 \mu \mathrm{m}$. $(\mathbf{c}, \mathbf{d})$ Depletion of K2:TEV depending on a destabilizing $\mathrm{N}$-terminal residue (F: phenylalanine) according to the $\mathrm{N}$-end rule. Methionine (M) as control. (c) Transfection into Drosophila Schneider 2 (S2) cells with 24-h recovery after transfection and 60-h post-transfection temperature shift from 16 to $29{ }^{\circ} \mathrm{C}$. (d) Drosophila flies were stably transformed with K2:TEV initiated by a Phe (F) residue or a M-K2:TEV control. Flies were subjected to shifts to permissive $\left(18^{\circ} \mathrm{C}\right)$ and restrictive temperatures $\left(29^{\circ} \mathrm{C}\right)$. Equal loading was further confirmed by staining of blotted membranes with probing against tubulin. $\mathrm{CBB}$,

Coomassie Brilliant Blue. 
temporally localize to the nucleus or cytosol, the compartments with high activity of the $\mathrm{N}$-end rule pathway or-in case for membrane localized proteins-have accessible $\mathrm{N}$ termini ${ }^{13}$; (3) a pre-selection via phenotype and/or western blotting after transformation helps to identify lines responding to the temperature alterations. The functionality of the system in organelles other than the cytosol or the nucleus where the action of the $\mathrm{N}$-end rule pathway is unclear such as endoplasmic reticulum and other membrane systems, mitochondria and chloroplasts is still to be determined.

Plant growth and development are known to be influenced by temperature ${ }^{18,41-44}$ and these topics are in the focus of current research. Detrimental side effects of temperature treatment may represent a downside of a temperature-induced approach, the impact of $29^{\circ} \mathrm{C}$ as a restrictive temperature on plant growth was documented (Figs 1 and 2, and Supplementary Figs 3 and 6). Effects of the plant high-temperature adaptation responses such as hypocotyl and petiole elongation, increased leaf size and earlier flowering have to be taken into consideration. Effects of elevated temperature on plant development and genetic control of plant thermomorphogenesis are currently matter of intense research ${ }^{45}$. However, all tested organisms were able to degrade the $K 2$ fusion proteins at restrictive temperature, and transcript levels remained stable over permissive and restrictive conditions. This suggests a low vulnerability of our lt-degron system to side effects related to growth differences caused by temperature.

In this study, the lt-degron enabled us to determine the temporal requirement of the transcriptional regulator TTG1 in the context of trichome development. With a switchable $\mathrm{CO}$ transcription factor, we controlled timing of flowering and generated specialized cell types and meristematic tissue of the flower on demand. An engineered conditional TEV protease offers opportunities for, for example, a facilitated downstreaming of recombinant proteins by intracellular self-cleavage directly in the expression host. K2:GUS temperature-shift experiments coupled to GUS activity measurements revealed that the lt-degron opens completely new avenues by, for example, testing the influence of various levels or pulses of conditionally accumulated proteins of interest in one stable genetic background without the need to generate a plethora of transgenic events.

Trichomes are very well-studied specialized model cells ${ }^{29}$ present on the surfaces of many plants and capable of synthesizing and either storing or secreting large amounts of specialized metabolites ${ }^{30}$. The use of the intrinsic metabolic capacity of trichomes to produce secondary metabolites or to enhance transcript levels of genes encoding enzymes required for biosynthesis of small molecules within trichomes has been discussed $^{46-49}$.

A special feature of using the heat-inducible $\mathrm{N}$-degron system in living organisms is that it allows conditional build-up of this cellular trichome compartment in the K2:TTG1 system. This could be used as a genetic background to globally switch ON/OFF a regulatory protein and establish a specific cellular reaction compartment or micro reactor. Such a cell population or tissue could harbour an enzymatic reaction cascade needed to build-up a molecule of interest, which is not necessarily a protein, which could potentially directly be influenced by the fusion to the lt-degron. Compartment-specific expression can be achieved by using compartment-specific promoters. Thus, the manufacture of biomolecules represents a possible scalable technical application as a production platform in the context of synthetic biology. We are convinced that the lt-degron is a powerful tool both for fundamental research in cell biology and developmental genetics but also has strong potential in biotechnological contexts like molecular farming of proteins or for metabolic engineering of small molecules. The conditional formation of trichomes in a trichome-lacking mutant or induced development of flowering tissue can be regarded as the design of a reaction compartment on demand, a tool to possibly form in vivo bioreactors.

\section{Methods}

Plant work. A. thaliana (L.) Heynh. plants were sown on soil mixture 1 (eight bags of MiniTray (70l per bag, Balster Einheitserdewerk); add $50 \mathrm{l}$ of water containing $800 \mathrm{ml}$ Osmocote Start (Scotts International) and $250 \mathrm{~g}$ BioMükk (Sautter and Stepper)), or on steamed (pasteurized for at least $3 \mathrm{~h}$ at $90{ }^{\circ} \mathrm{C}$ ) soil mixture 2 (Einheitserde Classic Kokos (45\% white peat, 20\% clay, 15\% block peat, $20 \%$ coco fibres; 10-00800-40, Einheitserdewerke Patzer); 25\% Vermiculite (grain size 2-3 mm; 29.060220, Gärtnereibedarf Kamlott) and 300-400 g Exemptor per $\mathrm{m}^{3}$ soil substrate ( $100 \mathrm{~g} \mathrm{~kg}^{-1}$ thiacloprid, 802288 , Hermann Meyer). After stratification of 4 to 5 days at $4{ }^{\circ} \mathrm{C}$ in the dark, seeds were germinated and plants grown under standard long-day $(16 / 8 \mathrm{~h}$ light/dark) or short-day $(8 / 16 \mathrm{~h}$ light/dark) greenhouse conditions between 18 and $25^{\circ} \mathrm{C}$. N. benthamiana (tobacco) plants were grown on soil mixture 2 .

For strictly controlled development such as during temperature-shift experiments, plants were grown either in growth cabinets (AR-66L2 and AR-66L3, Percival Scientific, CLF PlantClimatics) or in walk-in phyto chambers (Johnson Controls, equipped with ESC 300 software interface) at a humidity of $60 \%$ depending on the requirements, and watered with pre-warmed or pre-cooled tap water.

Seeds were plated either on soil or aseptically in vitro on plastic Petri dishes under long-day regime (16/8 h light/dark) on 0.5\% Murashige \& Skoog (MS; Duchefa Biochemicals, M0221) containing $1 \%$ sucrose and $8 \mathrm{gl}^{-1}$ phytoagar (Duchefa Biochemicals, P10031) in growth cabinets. For aseptic culture, dry seeds were sterilized with chlorine dioxide gas produced from 75\% Eau de Javel (Floreal Haagen) and $25 \% \mathrm{HCl}$. Selective MS media contained $10 \mathrm{mgl}^{-1} \mathrm{DL}$ -

phosphinotricin (PPT, Basta, glufosinate-ammonium, Duchefa Biochemicals),

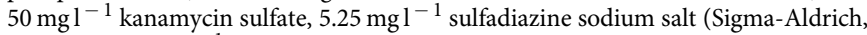
S6387) or $20 \mathrm{mgl}^{-1}$ hygromycine B (Duchefa Biochemicals, H0192). Bastaresistant plants were selected in solium in cotyledon stage by spraying $150 \mathrm{ml}$ per tray of a 1:1,000 dilution of Basta (contains $200 \mathrm{gl}^{-1}$ glufosinate-ammonium; Bayer CropScience) in tap water, which was repeated three times in a 2-day interval.

Plants used in this study were all in the background of the Columbia- 0 accession (Col-0) and either WT plants, T-DNA insertion mutants for TTG1 (ttg1, GABI_580A05, NASC stock ID: N455589, kindly provided by the GABI-Kat ${ }^{50}$ team via NASC-The European Arabidopsis Stock Centre, arabidopsis.info), ethyl methanesulfonate mutants for PRT1 (prt1 HygS or prt1-1, kind gift of Andreas Bachmair, Max F. Perutz Laboratories, Vienna, Austria) ${ }^{24-26}$ and 'TTG1-HA' is ttg1-13 Pro35S::TTG1-3xHA (kind gift of Martina Pesch, University of Cologne, Germany. ttg1-13 is a deletion line from fast-neutron bombardment, originally isolated from David Oppenheimer, University of Alabama, Tuscaloosa ${ }^{31}$.), which carries the TTG1 CDS in the backbone of $p A M-P A T-G W-3 x H A$ (see below for plasmid details) under control of the CaMV 35S promotor (Pro35S) and carrying the bar resistance marker (Laurent D. Noël and Jane Parker, Max Planck Institute for Plant Breeding Research, Cologne, Germany)), which was used as a negative control for a temperature-dependent destabilization of TTG1. Leaves 3/4 of the ttg 1 mutant show few undifferentiated stichel-like trichomes or initiation sites at the rim of the leaf, but neither initiation sites proximal to the midvein nor further differentiated trichomes (Figs $1 \mathrm{c}$ and $2 \mathrm{a}$ ). The central parts remain glabrous ${ }^{31}$. All plant strains used are listed in Supplementary Table 3.

For cryo scanning electron micrographs (SEMs), 5- to 7-day-old plants (pulses; Fig. 2b or 2-week-old plants (shifts; Fig. 2c) were treated for the indicated time. First, leaves were not yet visible at the time of the pulse experiments. Before protein isolation, transgenic plants were subjected to temperature shifts by removing the potted plants constantly grown at the indicated starting temperature $\left(16^{\circ} \mathrm{C}\right.$ in Fig. $2 \mathrm{~b}$ or $29^{\circ} \mathrm{C}$ in Fig. $2 \mathrm{c}$ ) and shifting them to the corresponding destination temperature $\left(29^{\circ} \mathrm{C}\right.$ in Fig. $2 \mathrm{~b}$ or $16^{\circ} \mathrm{C}$ in Fig. $\left.2 \mathrm{c}\right)$. To achieve a rapid acclimatization, plants were immediately watered with water pre-warmed or pre-cooled to the final temperature.

DNA work and degron construct design. DNA cloning was performed following standard procedures using Escherichia coli strain DH5 $\alpha$ (Invitrogen). The constructs were generated by fusion PCR ( $P f u$ polymerase, fermentas) using the primer combinations according to Supplementary Table 4. All individual constructs designed for this study are schematically represented in Supplementary Fig. 2. DNA amplicons were purified with ExoSap-IT (USB) preceding fusion PCRs. All fusions were flanked by Gateway attB1/attB2 sites and recombined by BP reactions into pDONR201 (Invitrogen).

Constructs $K 1-K 3$ start with the strong CaMV 35 S promoter, a $3^{\prime}$-tobacco Omega $(\Omega)$ leader sequence for translation enhancing followed by a sequence encoding for a synthetic codon-optimized $U b$, a triplet for the destabilizing bulky and hydrophobic amino acid Phe (F), a short linker peptide ( $\mathrm{e}^{\mathrm{L}}$; translates to HGSGI $)^{34}$ to further expose the N-terminal residue, one of the three different temperature-sensitive mouse dihydrofolate reductase sequences $\left(D H F R^{t s}\right)$ triggering the protein unfolding response, a triple hemagglutinin (HA)-tag (HAT) 
for immunodetection and the gene of interest. All plant degron cassettes carry Phe as destabilizing $\mathrm{N}$-terminal residue, because it was shown to be recognized by the Arabidopsis N-end rule pathway ${ }^{24-26}$ but to also represent a strongly destabilizing N-terminal in other model systems ${ }^{6-9,25,26}$ (Fig. 1a,b and Supplementary Fig. 1).

Cassettes $K 1-K 3$ were based on a $5^{\prime}$-synthetic human $U b$ gene ${ }^{51}$ and an $\Omega$ leader sequence from $p R T U B 8$, a derivative of $p R T U B 1$ (refs 24,52). The leader contains the 20 nucleotides upstream of the start codon of tobacco mosaic virus strain U1 (ref. 53) HAT was amplified from pSKTag3SUM6 (kind gift of Andreas Bachmair). The differences of the three DHFR variants in K1-K3 were as follows.

For construct $K 1$, the yeast $\mathrm{N}$-degron cassette, the mouse $D H F R^{P 67 L}$ variant $^{1,23}$, was amplified from $p K L 187$ of the S. cerevisiae 'DEGRON-KIT' ('Kit for making CUP1 t.s. degrons by PCR', EUROSCARF, EUROpean Saccharomyces cerevisiae ARchive for Functional Analysis (web.uni-frankfurt.de/fb15/mikro/euroscarf/) $)^{54,55}$. $\Omega$ leader and Ub were amplified from $p R T U B 8$ with ND70/ND71, $D H F R^{P 67 L}$ from $p K L 187$ with ND72/ND73 and HAT from pSKTag3SUM6 with ND74/N138 (K1:CO) or N172 (K1:TTG1) introducing a NotI site. The short linker $\mathrm{e}^{\mathrm{L}}$ (translates to HGSGI) was adapted from previous studies on protein half-life ${ }^{34}$ and used to further expose the N-terminal Phe. The TTC triplet introducing Phe (F) at the Ub-DHFR junction and the sequence encoding $\mathrm{e}^{\mathrm{L}}$ were included in ND71/ND72. Final fusion PCRs were always accomplished using the most distal primer pairs. Cloning and sequencing primers are listed in Supplementary Table 4 and Supplementary Fig. 2.

$K 2$ is derived from $p J H 10^{m u t}$ ( $p J H 23$ ), containing a mutated mouse $D H F R^{T 39 A, E 173 D}$, which was isolated in the yeast mutagenesis screen (Supplementary Note 2$)^{33}$. The fusion partner fragments were generated analogous to construct $K 1$, that is, $\Omega$ leader and $U b$ were amplified with ND70/ND78, $D H F R^{T 39 A, E 173 D}$ from $p J H 10^{m u t}$ with ND79/ND80 and HAT with ND81/ND75 (K1:TTG1) or N138 (K1:CO). A point mutation within the $D H F R^{T 39 A, E 173 D}$ was corrected by site-directed mutagenesis using N158/N159 and PfuTurbo polymerase (Stratagene). TTG1 of K2:TTG1 contains two silent point mutations (A555G and C567T).

An Entry clone containing K2:TTG1 was used as a template for further K2:POIs. A Gateway-compatible Entry clone $p E N-L 1-K 2-L 2$ containing the K2 degron cassette including $\Omega$ to HAT was generated to construct K2:POI fusions by Gateway LR reactions. K2 was amplified from the previously described K2:PAT using primers $21 / 22$ containing attB1/attB2 recombination sites.

K3 contains a triple-mutated mouse DHFR. All degron constructs containing cassette $K 3$ are derived from the Entry vectors harbouring $K 2: T T G 1 / C O$, which were used as templates in site-directed mutagenesis (PfuTurbo, Stratagene) using ND68/ND69 introducing the additional mutation P67L. DHFR of K3 carries the two newly isolated mutations $D H F R^{T 39 A, E 173 D}$ plus $P 67 \mathrm{~L}$, the original mutation from the S. cerevisiae $\mathrm{N}$-degron ${ }^{1}$.

$K 4$ starts with the native DHFR and an N-terminal Met residue and is based on $p^{J H 10^{m u t}}\left(D_{H F R}^{T 39 A, E 173 D}\right)$ from the yeast screen (Supplementary Note 2$)^{33}$. DHFR was amplified with ND82/ND80 and HAT with ND81/N138 (K4:CO) or N172 (K4:TTG1). K2 and K3 lacking the N-terminal HGSGI linker following the destabilizing Phe residue were based on the corresponding $K 2$ and $K 3$ fusions with TTG1 and CO. To alter the Ub-Phe-DHFR junction, TR01 and TR02 were designed for fusion PCR.

Plant expression constructs. Arabidopsis TTG1 and CO cDNAs (AT5G24520 and AT5G15840; kind gifts of Daniel Buoyer, University of Cologne, and Laurent Corbesier, Max Planck Institute for Plant Breeding Research, Cologne) were amplified with N173/ND77 (K1:TTG1 and K4:TTG1), with ND76/ND77 (K2:TTG1 and K3:TTG1) and with N139/N140 (K1:CO, K2:CO, K3:CO and K4:CO).

These degron:POI fusion proteins were subcloned into pDONR201 (Invitrogen) and the Entry clones sequenced (Supplementary Table 5). For stable expression in transgenic plants, Entry clones were recombined in an LR reaction into the attR site-containing binary Gateway destination vector PLEELA (ref. 56), containing a double CaMV $35 \mathrm{~S}$ promoter fused to the first WRYKY33 intron or into $P A M-P A T$ GW-ProUBQ10 (generated and kindly provided by Stefan Pusch, Deutsches Krebsforschungszentrum, Heidelberg). These Gateway-compatible Destination vectors are derived from $P A M-P A T-M C S$ (multiple cloning site; GenBank accession number AY436765), derivative of $p P A M$ (GenBank accession number

AY027531 $)^{57}$. These backbones carry the Streptomyces hygroscopicus bar gene that translates to phosphinothricin- $N$-acetyltransferase (PAT) as plant selection marker conferring resistance towards PPT. The vector backbone of $p A M-P A T-G W$ ProUBQ10 contains an insertion of 132 bp between the UBQ10 promoter and the attR1 site. The insertion is part of the promoter of TOO MANY MOUTHS (AT1G80080) and located after the $5^{\prime}$-XhoI site used to insert the UBQ10 promoter into the $P A M-P A T-G W$ backbone. The insertion does not result in alternative translation products since it includes stop codons in all reading frames.

For K2:GFP, $p E N-L 1-K 2-L 2$ was recombined with $p A M-K a n-35 S-G W-G F P$ (kind gift of Jane Parker), also a derivative of $P A M-P A T-M C S$.

K2:GUS was assembled by amplifying K2 with ND70/TR08 from K2:TTG1, as well as by TR07/TR06, which amplifies GUS from pENTR-gus (uidA $\mathrm{CDS}^{58}$ in pDONR201 (carries a $\operatorname{Val}(\mathrm{GtC}) 2 \mathrm{Leu}(\mathrm{TtA})$ and a silent Gaa $>$ Caa substitution for Glu279)). K2:GUS was fused using ND70/TR06 and introduced into $p A M-P A T$ GW ProUBQ10 by LR.

For $K 2: T E V, K 2$ was amplified from $K 2: T T G 1$ with primers $41 / 36$. TEV was isolated from $p C T 190-6$ (ref. 19) with primers 46/29, generating linker sequence 'L4' comprising HAT and hexahistidine tags. pCT190-6 carries a TEV-containing fusion protein in $p R S 416, \mathrm{TEV}$ is a more stable, autoinhibition-resistant mutated (S219V) catalytic domain variant ${ }^{59} . K 2$ and $T E V$ were fused with primers $41 / 29$, and Taq was added for a final 15 -min adenylation step at $72^{\circ} \mathrm{C}$. The $K 2: T E V$ product was incompatible with Gateway ENTR vectors suggesting that the TEV sequence interferes with plasmid stability. Thus, K2:TEV was cloned into pCRII-TOPO (Invitrogen) by TOPO cloning between the XhoI and SpeI. To construct a binary plant expression vector, K2:TEV was then cloned into pAM-PAT-MCS using the $5^{\prime}$ - and $3^{\prime}$-EcoRI sites from $p C R I I-T O P O$.

$K 2$ for K2:PAT was amplified from K2:TTG1 with ND70/TR11, bar (encodes PAT) from pLEELA with TR10/TR09, and fused with ND70/TR09. To receive a kanamycin-selectable binary plant expression vector, K2:PAT was recombined into pJan33 (double CaMV 35S promoter fused to the first WRYKY33 intron, selectable marker NPTII; kind gift of Marc Jakoby, University of Cologne).

S. cerevisiae constructs. Plasmids are derivatives of $p R S 314$ (CEN-ARS-TRP1) or pRS315 (pJH10, CEN-ARS-LEU2) ${ }^{60}$. DHFR-HA-URA3 was assembled by inserting copper-inducible promoter $\mathrm{P}_{C U P I}$ as a NotI-EcoRI fragment, Ub-F-DHFR as EcoRI-BamHI fragment from $P J H 10$ (WT DHFR), DHFR ${ }^{P 67 L}$ (same as in K1), pJH10 ${ }^{\text {mutC } 33}$ containing the $D H F R^{T 39 A, E 173 D}$ variant (same as in K2; Supplementary Note 2) and HA-URA3 as BamHI-KpnI fragment into the polylinker of $p R S 314$ serving as templates for $p J D 646(U b-F-D H F R-w t)$, pJD647 $(U b-F-D H F R-P 67 L=K 1)$ and $p J D 648(U b-F-D H F R-T 39 A, E 173 D=K 2)$. Yeast strains used are listed in Supplementary Table 3 . Standard media were YPD medium and ammonia-based synthetic complete (SC) dextrose.

For spot growth assays, yeast cultures were grown overnight in liquid culture and exponentially growing cells serially diluted to $5,000 / 1,000 / 200 / 40 / 8$ cells per $\mu \mathrm{l}$ (1:5 steps). A volume of $1 \mu \mathrm{l}$ of the suspension was spotted with a pin-frogger onto plates containing yeast standard minimal medium/synthetic defined (SD) and grown for 3-5 days.

For cycloheximide (CHX) chase experiments, exponentially growing yeast cultures were supplemented with $100 \mu \mathrm{g} \mathrm{ml}^{-1} \mathrm{CHX}$; samples collected at different time-points, pelleted, washed and frozen in liquid $\mathrm{N}_{2}$. The cells were lysed by incubating them in Laemmli loading buffer at $100^{\circ} \mathrm{C}$ for $5 \mathrm{~min}$. Extracts were analysed by SDS-polyacrylamide gel electrophoresis (SDS-PAGE) and two-colour western blotting using the Odyssey Infrared Imaging System (Li-Cor). Mouse monoclonal anti-HA epitope tag antibody (HA.11, clone 16B12, MMS-101R, BioLegend) in combination with an IRDye 800-coupled rat anti-mouse IgG (Rockland) was used for detecting tagged DHFR-HA-URA3 proteins. A rabbit polyclonal anti-Cdc11 antibody (y-415: sc-7170, Santa Cruz Biotechnology) was used for detecting CDC11 in combination with an Alexa Fluor 680-coupled goat anti-rabbit IgG antibody (Biomol), which served as an internal protein-loading control ${ }^{61}$.

Drosophila constructs. For expression of K2:GFP in Drosophila cell culture, $K 2$ from $p E N-L 1-K 2-L 2$ was introduced into $p A W G$ (Drosophila Genomics Resource Center (DGRC), Indiana University, Bloomington, USA; https:// dgrc.cgb.indiana.edu/product/View?product=1072; Stock Number: 1072; Murphy, T.D. et al., Construction and application of a set of Gateway vectors for expression of tagged proteins in Drosophila, unpublished data) via a Gateway LR reaction. $p A W G$ contains an Actin $5 c$ promoter upstream of the Gateway cassette and a C-terminal eGFP tag. ProActin5c::K2:TEV for cell culture transfection and transformation of flies contains $D H F R^{T 39 A, E 173 D}$, amplified from K2:TTG1 using primers 36/37 (Phe-K2) or 36/38 (Met-K2). Ub from S. cerevisiae ${ }^{4}$ was used and amplified with primers $9 / 39$ (Phe-K2) or 9/40 (Met-K2). The fragments were fused to $U b: X-D H F R^{T 39 A, E 173 D}$ with primers $9 / 36$. TEV was amplified from $p C T 190-6$ with primers $46 / 29$ and $K 2$ fused with primers $9 / 29$. Taq polymerase was added for a final 15 -min adenylation step at $72{ }^{\circ} \mathrm{C}$. The construct was subcloned in pCRII-TOPO. K2:TEV was incompatible with Gateway recombination and the construct prepared as XhoI-SpeI fragment, which was partially cut to leave an internal SpeI site unaffected. The fragment was ligated into $p A W$ (DGRC; https:// dgrc.cgb.indiana.edu/product/View?product=1127; Stock Number: 1127). $p A W$ contains the Actin $5 c$ promoter upstream of the Gateway cassette and was cut with XhoI and NheI to lose the Gateway cassette and yield the Actin $5 c$-driven fly expression vector.

Stable plant transformation and selection of transformants. The binary plant expression vectors were retransformed into Agrobacterium tumefaciens GV3101-pMP90RK (C58C1 Rif $\left.\mathrm{Gm}^{r} \mathrm{Km}^{r}\right)^{62}$ to obtain a bacterial transformation suspension. The identity of the Agrobacterium strains was verified by backtransformation of isolated plasmid into E. coli $\mathrm{DH} 5 \alpha$ and at least three independent analytical digestions. All constructs were transformed by a modified version of the floral dip method ${ }^{63}$.

Individual T1 (generation 1 after transformation) transgenic plant lines were pre-selected with Basta or kanamycin as described above. To exclude lines showing position effects, for example, by disrupting essential genes by the construct T-DNA the number of insertion loci was determined in a segregation analysis in the T2 generation and only transgenic plants carrying one single insertion locus were further used. Standard lines were established by isolating T3 plants homozygous for the transgene. Independent representative reference lines displaying a typical conditional phenotype on temperature up- and downshifts were used in the final 
experiments. Standard lines were established by isolating T3 plants homozygous for the transgene.

To identify responsive transgenic lines, we prescreened TTG1-td, CO- $t d$, GUS- $t d$ and PAT- $t d$ by developmental and histological phenotype and TEV-td and GFP- $t d$ by western blotting.

Transient transfection of $\mathbf{N}$. benthamiana. For transient transformation of tobacco, leaves of 4-week-old plants were infiltrated with Agrobacteria GV3101pMP90RK, carrying binary plant expression vectors. Agrobacteria were grown to the stationary phase overnight in $10 \mathrm{ml}$ of YEB medium and pelleted at $5,000 \mathrm{~g}$ at room temperature. The pellet was washed once in $10 \mathrm{ml}$ of infiltration buffer (10 mM MES (pH 5.6), $10 \mathrm{mM} \mathrm{MgSO} 4,100 \mu \mathrm{M}$ acetosyringone (D134406, Sigma)) and subsequently resuspended in $10 \mathrm{ml}$ of the same buffer. Agrobacteria strains were co-infiltrated with $p 19$, an A. tumefaciens strain based on GV3101 carrying pBIN6Ip19 containing the $p 19$ protein of tomato bushy stunt virus to suppress post-transcriptional gene silencing and increase ectopic gene expression ${ }^{64}$. Before infiltration, bacteria suspensions were adjusted to an $\mathrm{OD}_{600}$ of 0.5 . Desired bacteria suspensions were then mixed with $p 19$ bacteria suspension to a final $\mathrm{OD}_{600}$ value of 0.25 for both components. Bacteria suspensions were then infiltrated into the epidermis on the lower side of the tobacco leaf. Infiltrated areas were marked on the upper side of the leaf with a permanent marker. For an easier infiltration procedure, plants were watered and transferred to standard greenhouse long-day conditions the day before to allow plant stomata to open. To allow efficient transformation and expression, plants were kept for $48 \mathrm{~h}$ in the greenhouse, before applying temperature shift experiments by transferring them into a growth cabinet at either permissive or restrictive growth conditions. For one data point, 15-20 leaf discs of $5 \mathrm{~mm}$ diameter were collected from infiltrated areas and snap-frozen in liquid nitrogen. Extraction was performed using radioimmunoprecipitation assay (RIPA) buffer as mentioned below.

Drosophila cell culture work. D. melanogaster Kc embryonic tissue culture cells ${ }^{65}$ or Schneider 2 (S2) cells ${ }^{66}$ (Invitrogen) were grown at $24^{\circ} \mathrm{C}$ in $3 \mathrm{ml}$ of Schneider's medium (Gibco) supplemented with $10 \%$ fetal bovine serum. Cells were passaged into fresh media every 5 days in a 1:10 dilution. Transfection was carried out in a 12-well dish using the Effectene transfection kit (Qiagen) according to the manufacturer's protocol for adherent cells. Temperature treatments and shifts from $24^{\circ} \mathrm{C}$ to the desired temperature were carried out at 15 or $16^{\circ} \mathrm{C}$ versus $29^{\circ} \mathrm{C}$. The details of the temperature-shift experiments are indicated in the figure legend. CHX chase was performed with $100 \mu \mathrm{g} \mathrm{ml}^{-1}$ in dimethylsulfoxide (DMSO).

\section{Drosophila transformation and characterization. Vectors carrying} Actin5c::Phe-K2:TEV (F-K2:TEV) or Actin5c::Met-K2:TEV (M-K2:TEV) were injected in $\mathrm{ZH}$-attP-2A or $\mathrm{ZH}$-attP-51D embryos according to the phiC31 recombinase transgenesis system ${ }^{67}$. In brief, 1-h-old embryos were collected, placed on slides and immersed in injection oil. The plasmids were injected in the posterior region of the embryo aiming at the area where the pole cells would develop. Hatched larvae were collected and placed on standard Drosophila medium based on a mixture of cornmeal, yeast, agar, sucrose, soy flour and water. Transformants were grown at $25^{\circ} \mathrm{C}$ standard conditions. Adult flies were shifted either to 18 or $29^{\circ} \mathrm{C}$. After $24 \mathrm{~h}$, total protein extracts were obtained from whole flies homogenized in standard lysis buffer (20 mM Tris-Cl (pH 7.5), $200 \mathrm{mM} \mathrm{NaCl}$, $2 \mathrm{mM}$ EDTA, $10 \%$ glycerol, 1\% Nonidet P-40 and EDTA-free Complete Protease Inhibitor Cocktail (Roche Diagnostics)).

Protein extraction and western blot analysis. Plant tissue (Arabidopsis: leafs or seedlings, tobacco: leaf discs) was collected in a standard $2 \mathrm{ml}$ reaction tube containing three Nirosta stainless steel beads ( $3.175 \mathrm{~mm}$; 75306, Mühlmeier), snap-frozen in liquid $\mathrm{N}_{2}$ and stored at $-80^{\circ} \mathrm{C}$. Material was ground frozen using a bead mill (Retsch, MM400; $45 \mathrm{~s}, 30 \mathrm{~Hz}$ ) in collection microtube blocks (adaptor set from TissueLyser II, 69984, Qiagen).

For K2:TTG1 time courses, per time point, one leaf was ground in $200 \mu \mathrm{l}$ of extraction buffer ( $50 \mathrm{mM}$ Tris-Cl ( $\mathrm{pH} 7.6$ ), $150 \mathrm{mM} \mathrm{NaCl}, 5 \mathrm{mM}$ EDTA, $0.1 \%$ SDS, $0.1 \%$ 3 -mercaptoethanol and EDTA-free Complete Protease Inhibitor Cocktail). Alternatively, tissue was lysed using RIPA buffer (50 mM Tris-Cl (pH 8), $120 \mathrm{mM}$ $\mathrm{NaCl}, 20 \mathrm{mM} \mathrm{NaF}, 1 \mathrm{mM}$ EDTA, $6 \mathrm{mM}$ EGTA, $1 \mathrm{mM}$ benzamidine hydrochloride, $15 \mathrm{mM} \mathrm{Na}_{4} \mathrm{P}_{2} \mathrm{O}_{7}$ and $1 \%$ Nonidet P-40 supplemented with EDTA-free Complete Protease Inhibitor cocktail added freshly).

Extraction of K2:TEV was done in $25 \mathrm{mM}$ Tris- $\mathrm{Cl}$ (pH 7.5), $75 \mathrm{mM} \mathrm{NaCl}$, $15 \mathrm{mM} \mathrm{MgCl}_{2}, 15 \mathrm{mM}$ EGTA ( $\mathrm{pH}$ 8.0), 0.1\% Tween 20, 0.1\% Triton X-100, $5 \mathrm{mM}$ dithiothreitol and EDTA-free Complete Protease Inhibitor Cocktail in a chilled cooling block at $4{ }^{\circ} \mathrm{C}, 800$ r.p.m. for $30 \mathrm{~min}$. Insoluble cell debris was pelleted via centrifugation for $20 \mathrm{~min}$ at $4{ }^{\circ} \mathrm{C}, 20,000 \mathrm{~g}$. The protein content of the samples was determined using a DirectDetect infrared spectrophotometer (MerckMillipore).

Drosophila cells were transferred into a standard $1.5 \mathrm{ml}$ reaction tube and collected via centrifugation at $4^{\circ} \mathrm{C}$ for $5 \mathrm{~min}, 300 \mathrm{~g}$. The pellet was washed once with ice-cold PBS and cells lysed using RIPA buffer. Following steps were carried out as described above.

Drosophila pupae were lysed as described above and western blots performed with rabbit polyclonal anti-HA epitope tag antibody (Y-11: sc-805, Santa Cruz
Biotechnology) or rabbit polyclonal $\alpha$-Tubulin antibody (H-300: sc-5546, Santa Cruz Biotechnology) and detected by enhanced chemiluminescence (ECL).

$S$. cerevisiae cells were grown at $30^{\circ} \mathrm{C}$ to logarithmic growth phase, and $\mathrm{CHX}$ added to the cultures to a final concentration of $100 \mathrm{mgl}^{-1}$. Strains were expanded at $25^{\circ} \mathrm{C}$ and incubated at $37^{\circ} \mathrm{C}$ for $30 \mathrm{~min}$ before $\mathrm{CHX}$ addition. Proteins were extracted from 5 to $50 \mathrm{ml}$ of exponentially growing suspension culture $\left(\mathrm{OD}_{600}=0.8-1.2\right)$ by centrifugation and grinding with glass beads $(5 \mathrm{~min}$, IKAVibrax-VXR, Janke und Kunkel) at $4{ }^{\circ} \mathrm{C}$ in $150-300 \mu$ l Native lysis buffer (50 mM Na-HEPES (pH 7.5); $150 \mathrm{mM} \mathrm{NaCl,} 5$ mM EDTA, 1\% Triton X-100, containing EDTA-free Complete Protease Inhibitor Cocktail, $20 \mu \mathrm{M}$ MG132) followed by a second centrifugation $\left(4^{\circ} \mathrm{C}, 10 \mathrm{~min}, 20,000 \mathrm{~g}\right)$. Proteins were separated by SDS-PAGE and analysed by quantitative western blotting ${ }^{61}$ using an LAS1000 system (Fuji).

Equal protein amounts were resolved by $10 \%$ (GUS) or $12 \%$ (all others) SDS-PAGE. Blotting of TTG1 and CO samples was done on nitrocellulose transfer membrane by wet blot in a tank blotter (SCIE-PLAS EB10) ${ }^{63}$. All other samples were blotted onto polyvinylidene fluoride transfer membrane by semi-dry blot using a Trans-Blot SD semi-dry electrophoretic transfer cell (170-3940, Bio-Rad).

Equal loading and general protein abundance was confirmed by staining of the blotted and probed membranes after immunostaining with Ponceau S (sodium salt) or Coomassie Brilliant Blue G250 (CBB G150). All antibodies used including parameters are listed in Supplementary Table 6. All degron constructs can be detected with mouse monoclonal anti-DHFR antibody (A-4: sc-74593, Santa Cruz Biotechnology) and mouse monoclonal anti-HA epitope tag antibody (HA.11, clone 16B12: MMS-101R, BioLegend), or rat monoclonal anti-HA epitope tag antibody (High Affinity, clone 3F10: 11867423 001, Roche Diagnostics). Horseradish peroxidase-conjugated secondary antibodies (Supplementary Table 6) were detected by ECL using ECL SuperSignal West Pico or Femto (34087 or 34096, Pierce) followed by exposure on autoradiography film. Colorimetric detection of alkaline phosphatase-labelled antibody (Supplementary Table 6) via the nitroblue tetrazolium chloride/5-bromo-4-chloro-3-indolyl phosphate $p$-toluidine (NBT/BCIP) substrate system by tetrazolium precipitation with NBT/BCIP reaction buffer $(100 \mathrm{mM}$ Tris-Cl ( $\mathrm{pH} 9.5), 100 \mathrm{mM} \mathrm{NaCl}, 50 \mathrm{mM} \mathrm{MgCl} 2,400 \mu \mathrm{M}$

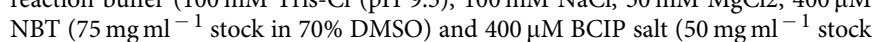
in DMSO). Staining was done until colour developed and the reaction stopped in $20 \mathrm{mM}$ EDTA in tris-buffered saline (TBS) ( $\mathrm{pH} \mathrm{8.0)}$ and by washing for three times in water. Western data were confirmed by analysis of at least three biological replicates. Full blot and gel images are provided in Supplementary Fig. 8.

In situ glucoronidase histology. Two- to three-week-old plants were collected and submerged in GUS staining solution ( $1 \mathrm{mM} \mathrm{X-Gluc} \mathrm{(X-glucuronide} \mathrm{sodium}$ salt)). ${ }^{68}$ After vacuum infiltration for $30 \mathrm{~min}$, samples were incubated overnight at $37^{\circ} \mathrm{C}$, fixed and cleared in GUS fixation solution (9:1 ethanol/glacial acetic acid for $4 \mathrm{~h} /$ room temperature) and stored in $70 \%$ ethanol.

Quantification of glucoronidase activity. At least five seedlings/sample were collected, pooled and snap-frozen in liquid $\mathrm{N}_{2}$. Proteins from 2-week-old K2:GUS seedlings were extracted in GUS extraction buffer $(50 \mathrm{mM} \mathrm{Na}$-phosphate, $10 \mathrm{mM}$ EDTA, $0.1 \%$ SDS, $0.1 \%$ Triton X-100 and freshly added $10 \mathrm{mM} \beta$-mercaptoethanol and EDTA-free protease inhibitor cocktail $)^{68}$. A volume of $196 \mu$ l assay solution (1 mM 4-methylumbelliferyl- $\beta$-D-glucuronide (4-MUG)) were mixed with $4 \mu \mathrm{l}$ of protein extract in a white 96-well plate (Nunc FluoroNunc, Thermo Scientific) for the assay. Fluorometric measurements were done at $37^{\circ} \mathrm{C}$ in a spectrophotometer (M1000, Tecan) for $60 \mathrm{~min}$, one data point was taken per minute. Hydrolysis of 4-MUG by GUS generates the aglycone 4-methylumbelliferone (4-MU), which gives a detectable fluorescent emission at $455 \mathrm{~nm}$ after excitation at $365 \mathrm{~nm}$. Owing to the online fluorescence measurement of increasing 4-MU, the reaction samples did not have to be separately stopped with $0.2 \mathrm{M} \mathrm{Na}_{2} \mathrm{CO}_{3}$ after $60 \mathrm{~min}$ as described in the original protocol. Samples were measured for a total of $60 \mathrm{~min}$ with one data point taken every minute and normalized to a 4-MU standard. Activity was determined as pmol 4-MU per min and $\mathrm{mg}$ of total protein. Control plants expressing Pro35S::GUS from the binary plasmid pBI121 (ref. 69) were a kind gift of Diana Schmidt (Leibniz Institute of Plant Biochemistry, Halle).

Degron tuning assay. For the time-course K2:GUS experiment, plants were grown aseptically on MS-containing Petri dishes (see above) including $10 \mathrm{mgl}^{-1}$ PPT for 2 weeks at either permissive or restrictive temperatures. A first sample (at least five seedlings) was taken and snap-frozen in liquid $\mathrm{N}_{2}$. Then, the temperature was increased or decreased by $2.8^{\circ} \mathrm{C}$, depending on the design of the time course (warm-cold-warm or cold-warm-cold), and kept for $24 \mathrm{~h}$. Every $24 \mathrm{~h}$, samples were taken before the new temperature change. The time frame allowed plants to run one complete day/night cycle, acclimatize and appropriately express/stabilize protein. The activity was measured as indicated above, all three biological replicates $(n=3)$ consisting of independent plant material were individually measured as three technical replicates.

Immunoprecipitation for mass spectrometry. K2:GUS plants were grown on plates on $0.5 \% \mathrm{MS}$ containing PPT at permissive temperature $\left(13^{\circ} \mathrm{C}\right)$ for 2 weeks, collected and frozen in liquid $\mathrm{N}_{2}$. After milling (see above), plant material was lysed 
and proteins extracted with extraction buffer containing phosphatase inhibitors and cleared twice by centrifugation $\left(4^{\circ} \mathrm{C}, 20,000 \mathrm{~g}\right)^{70,71}$. Per sample, two microcentrifuge tubes were prepared, each containing $250 \mu$ lof lysate at a concentration of $1.5 \mu \mathrm{g}$ total protein per $\mu$ l. Preclearing of sepharose matrix (nProtein A Sepharose 4 Fast Flow, GE Healthcare Life Sciences) was performed for $2 \mathrm{~h}$ on a rotating wheel at $4{ }^{\circ} \mathrm{C}$ with $100 \mu \mathrm{l}$ of $50 \%$ bead slurry/reaction. After a centrifugation step $\left(4^{\circ} \mathrm{C}, 5 \mathrm{~min}, 20,000 \mathrm{~g}\right)$, the supernatant was transferred into a new tube and $50 \mu \mathrm{l}$ of anti-DHFR antibody (A-4: sc-74593, Santa Cruz Biotechnology) were added per reaction. Samples were incubated overnight on a rotating wheel at $4{ }^{\circ} \mathrm{C}$. A volume of $250 \mu \mathrm{l}$ of $50 \%$ bead slurry were then added and incubated for $3 \mathrm{~h}$ rotating at $4^{\circ} \mathrm{C}$. Beads were centrifuged $\left(4^{\circ} \mathrm{C}, 400 \mathrm{~g}, 2 \mathrm{~min}\right)$ and washed 3 times with $1 \mathrm{ml}$ of bead buffer ${ }^{70,71}$. Beads were boiled for $15 \mathrm{~min}$ in $30 \mu \mathrm{l}$ of $5 \times$ SDS loading dye, centrifuged $(5 \mathrm{~min}, 20,000 \mathrm{~g}$ ) and the supernatants of two reactions pooled. A volume of $5 \mu \mathrm{l}$ of the supernatant were loaded on a 6\% PAGE gel and subjected to western blotting with rabbit anti-HA antibody (HA.11, clone 16B12: MMS-101R, BioLegend) to confirm running parameters of the different K2:GUS bands. The rest of the supernatant was separated via SDS-PAGE and silver-stained using an MS compatible staining protocol in an overall volume of $25 \mathrm{ml}$ per gel. The gel was incubated twice for $20 \mathrm{~min}$ in aqueous fixing solution ( $40 \%$ methanol and $10 \%$ glacial acetic acid), pretreated for $30 \mathrm{~min}$ in $0.8 \mathrm{mM}$ $\mathrm{Na}_{2} \mathrm{~S}_{2} \mathrm{O}_{3}, 0.8 \mathrm{M} \mathrm{CH}_{3} \mathrm{COONa}$ and $30 \%$ methanol, washed for three times in water for $5 \mathrm{~min}$, stained for $20 \mathrm{~min}$ in $12 \mathrm{mM} \mathrm{AgNO}_{3}$, developed for maximum $5 \mathrm{~min}$ in $0.2 \mathrm{M} \mathrm{NaCO}_{3}, 0.04 \%$ formaldehyde, stopped for $10 \mathrm{~min}$ in $0.3 \mathrm{M} \mathrm{Na}_{2}$-EDTA and washed for two times in water for $10 \mathrm{~min}$. The stained gel can be conserved overnight or longer in $25 \%$ ethanol, $3 \%$ glycerol and $72 \%$ water. Three lanes were excised (Supplementary Fig. 7). Liquid chromatography-mass spectrometric (LC-MS) analysis was carried out as follows.

LC-MS analysis. Cysteine side chains were reduced and alkylated, proteins digested with trypsin overnight and peptides extracted and dried in a concentrator. Peptides were dissolved in 5\% acetonitrile and $0.1 \%$ trifluoroacetic acid, and injected into an EASY nano-LCII chromatography system (Thermo Fisher). Reverse phase chromatography was performed using an EASY column SC200 $(10 \mathrm{~cm}$, inner diameter: $75 \mu \mathrm{m}$, particle size: $3 \mu \mathrm{m})$ using a pre-column (EASY column SC001, $2 \mathrm{~cm}$, inner diameter: $100 \mu \mathrm{m}$, particle size: $5 \mu \mathrm{m}$ ) and a mobile phase gradient from 5 to $40 \%$ acetonitrile, $0.1 \%$ trifluoroacetic acid in water in $150 \mathrm{~min}$ (flow rate of $300 \mathrm{nl} \mathrm{min}^{-1}$; all from Thermo Fisher). Peptides were electrosprayed on-line into an LTQ-OrbiTrap Velos Pro mass spectrometer (Thermo Fisher; spray voltage of $1.9 \mathrm{kV}$ ). Orbitrap (Fourier transform, FT) and ion trap (IT) injection waveforms were enabled, one micro scan acquired for all scan types, FT master scan preview and charge state screening enabled; singly charged ions were rejected in data-dependent acquisition (DDA) analysis. The mass spectrometer was calibrated with $\mathrm{m} / z$ of $445.120024 \mathrm{Th}$. Data-dependent MS/MS spectral acquisition of the 20 most abundant ion signals was performed in the full scan. SwissProt protein sequence database (535,248 sequences; $189,901,164$ residues) was searched with MS/MS spectra using Mascot (matrix Science, Proteome Discoverer v.1.4; Thermo Fisher) to identify Ub, DHFR and GUS peptides. The enzyme was set to trypsin, two missed cleavages tolerated, precursor tolerance set to 7 p.p.m., fragment ion tolerance to $0.8 \mathrm{Th}$, and the family-wise error rate controlled using a $1 \%$ peptide false discovery rate.

Proteasome inhibitor experiments. Seedlings were grown in liquid culture in 50 - $\mathrm{ml}$ Erlenmeyer flasks in $20 \mathrm{ml}$ of $0.5 \%$ MS including vitamins (Duchefa Biochemicals, M0222), $0.25 \%$ sucrose, $500 \mathrm{mgl}^{-1} \mathrm{MES}$ (2-(N-Morpholino)-ethane sulfonic acid, Carl Roth, 4256) and $10 \mathrm{mgl}^{-1}$ PPT for 2 weeks at permissive or restrictive temperature. Before treatment, seedlings were transferred into 12-well microplates (Greiner) into $5 \mathrm{ml}$ of medium and treated with $5 \mu \mathrm{M}$ of MG132 (UBPBio) in DMSO ( $5 \mu \mathrm{l}$ of a $50 \mathrm{mM}$ stock per $5 \mathrm{ml}$ medium). Mock-treated samples were supplemented with an equivalent volume of DMSO. Plates were incubated for $5 \mathrm{~h}$, collected, frozen in liquid $\mathrm{N}_{2}$ and proteins extracted with RIPA buffer. After protein quantification with bicinchoninic acid assay (Thermo Scientific), $20 \mu \mathrm{g}$ of total protein were loaded per lane, separated on a $10 \%$ SDS-PAGE, blotted and probed as described above.

RNA work and RT-PCR. Two-week-old seedlings were collected and snap-frozen. After milling, about $50 \mathrm{mg}$ of tissue was used for RNA extraction with RNeasy Plant Mini Kit (Qiagen). RNA was measured with a spectrophotometer and quality assessed via agarose gel electrophoresis. For first-strand cDNA synthesis, $500 \mathrm{ng}$ of total RNA were used with an equimolar mixture of four oligo(dT) primers (CDSIII-NotIA/C/G/T, Supplementary Table 7) and RevertAid H Minus Reverse Transcriptase (Thermo Scientific). A volume of $1 \mu \mathrm{l}$ of cDNA was used for PCR analysis using self-made Taq in two reactions per sample; one with generic degron-specific primers (DHFR_frw/DHFR_rev) to test transcript levels of the transgene and one with intron-spanning primers EF1ss/EFlas for ELONGATION FACTOR 1 (EF1) as a housekeeping gene (amplicon sizes: genomic $810 \mathrm{bp}$; cDNA $709 \mathrm{bp}$ ). Both PCRs were run for 30 cycles. Oligonucleotide primers used for RTPCR are listed in Supplementary Table 7.

Microscopy. SEM was done with a SUPRA 40VP (Carl Zeiss MicroImaging) equipped with a K1250X Cryogenic SEM Preparation System (EMITECH), a CPD
030 critical point dryer (Bal-Tec) and a SC 7600 sputter coater (Polaron) at the on-campus microscopy core facility Zentrale Mikroskopie (CeMic) of the Max Planck Institute for Plant Breeding Research, Cologne. Light and confocal laser scanning microscopy was performed with an LSM710 system (Carl Zeiss MicroImaging). K2:GFP fluorescence was observed in root tips of plants that were aseptically grown for 2 weeks under long-day conditions at either constitutively restrictive or permissive temperatures on $0.5 \mathrm{MS}$ medium containing $50 \mathrm{mgl}^{-1}$ kanamycin sulfate. Photographs of in vitro cultures and histological stainings were taken with a stereo microscope (Stemi 2000-C) equipped with a Zeiss CL 6000 LED illumination unit, and a video adapter $60 \mathrm{C}$ including an AxioCam ERc 5s digital camera (all from Carl Zeiss MicroImaging).

Data availability. The authors declare that the data supporting the findings of this study are available within the article and its Supplementary Information files or are available from the corresponding author on request.

\section{References}

1. Dohmen, R. J., Wu, P. \& Varshavsky, A. Heat-inducible degron: a method for constructing temperature-sensitive mutants. Science 263, 1273-1276 (1994).

2. Varshavsky, A. Naming a targeting signal. Cell 64, 13-15 (1991).

3. Johnson, E. S., Gonda, D. K. \& Varshavsky, A. cis-trans recognition and subunit-specific degradation of short-lived proteins. Nature 346, 287-291 (1990).

4. Bachmair, A., Finley, D. \& Varshavsky, A. In vivo half-life of a protein is a function of its amino-terminal residue. Science 234, 179-186 (1986).

5. Graciet, E., Mesiti, F. \& Wellmer, F. Structure and evolutionary conservation of the plant N-end rule pathway. Plant J. 61, 741-751 (2010).

6. Graciet, E. \& Wellmer, F. The plant N-end rule pathway: structure and functions. Trends Plant Sci. 15, 447-453 (2010).

7. Varshavsky, A. The N-end rule pathway and regulation by proteolysis. Protein Sci. 20, 1298-1345 (2011).

8. Tasaki, T., Sriram, S. M., Park, K. S. \& Kwon, Y. T. The N-end rule pathway. Annu. Rev. Biochem. 81, 261-289 (2012).

9. Gibbs, D. J., Bacardit, J., Bachmair, A. \& Holdsworth, M. J. The eukaryotic $\mathrm{N}$-end rule pathway: conserved mechanisms and diverse functions. Trends Cell Biol. 24, 603-611 (2014).

10. Heck, J. W., Cheung, S. K. \& Hampton, R. Y. Cytoplasmic protein quality control degradation mediated by parallel actions of the E3 ubiquitin ligases Ubr1 and San1. Proc. Natl Acad. Sci. USA 107, 1106-1111 (2010).

11. Nillegoda, N. B. et al. Ubrl and Ubr2 function in a quality control pathway for degradation of unfolded cytosolic proteins. Mol. Biol. Cell 21, 2102-2116 (2010).

12. Levy, F., Johnston, J. A. \& Varshavsky, A. Analysis of a conditional degradation signal in yeast and mammalian cells. Eur. J. Biochem. 259, 244-252 (1999).

13. Wittke, S., Lewke, N., Muller, S. \& Johnsson, N. Probing the molecular environment of membrane proteins in vivo. Mol. Biol. Cell 10, 2519-2530 (1999).

14. Baker, R. T., Smith, S. A., Marano, R., McKee, J. \& Board, P. G. Protein expression using cotranslational fusion and cleavage of ubiquitin. Mutagenesis of the glutathione-binding site of human Pi class glutathione S-transferase. $J$. Biol. Chem. 269, 25381-25386 (1994).

15. Parsell, D. A. \& Sauer, R. T. The structural stability of a protein is an important determinant of its proteolytic susceptibility in Escherichia coli. J. Biol. Chem. 264, 7590-7595 (1989).

16. Su, X., Bernal, J. A. \& Venkitaraman, A. R. Cell-cycle coordination between DNA replication and recombination revealed by a vertebrate $\mathrm{N}$-end rule degron-Rad51. Nat. Struct. Mol. Biol. 15, 1049-1058 (2008).

17. Bernal, J. A. \& Venkitaraman, A. R. A vertebrate $\mathrm{N}$-end rule degron reveals that Orc6 is required in mitosis for daughter cell abscission. J. Cell Biol. 192, 969978 (2011).

18. Larkindale, J., Hall, J. D., Knight, M. R. \& Vierling, E. Heat stress phenotypes of Arabidopsis mutants implicate multiple signaling pathways in the acquisition of thermotolerance. Plant Physiol. 138, 882-897 (2005).

19. Taxis, C., Stier, G., Spadaccini, R. \& Knop, M. Efficient protein depletion by genetically controlled deprotection of a dormant N-degron. Mol. Syst. Biol. 5, 267 (2009).

20. Banaszynski, L. A., Chen, L. C., Maynard-Smith, L. A., Ooi, A. G. \& Wandless, T. J. A rapid, reversible, and tunable method to regulate protein function in living cells using synthetic small molecules. Cell 126, 995-1004 (2006).

21. Nishimura, K., Fukagawa, T., Takisawa, H., Kakimoto, T. \& Kanemaki, M. An auxin-based degron system for the rapid depletion of proteins in nonplant cells. Nat. Methods 6, 917-922 (2009).

22. Faden, F., Mielke, S., Lange, D. \& Dissmeyer, N. Generic tools for conditionally altering protein abundance and phenotypes on demand. Biol. Chem. 395, 737-762 (2014)

23. Dohmen, R. J. \& Varshavsky, A. Heat-inducible degron and the making of conditional mutants. Methods Enzymol. 399, 799-822 (2005).

24. Bachmair, A., Becker, F. \& Schell, J. Use of a reporter transgene to generate arabidopsis mutants in ubiquitin-dependent protein degradation. Proc. Natl Acad. Sci. USA 90, 418-421 (1993). 
25. Potuschak, T. et al. PRT1 of Arabidopsis thaliana encodes a component of the plant N-end rule pathway. Proc. Natl Acad. Sci. USA 95, 7904-7908 (1998).

26. Stary, S. et al. PRT1 of Arabidopsis is a ubiquitin protein ligase of the plant $\mathrm{N}$-end rule pathway with specificity for aromatic amino-terminal residues. Plant Physiol. 133, 1360-1366 (2003).

27. Marks, M. D. Molecular genetic analysis of trichome development in Arabidopsis. Annu. Rev. Plant Physiol. Plant Mol. Biol. 48, 137-163 (1997)

28. Oppenheimer, D. G. Genetics of plant cell shape. Curr. Opin. Plant Biol. 1, 520-524 (1998).

29. Hülskamp, M. Plant trichomes: a model for cell differentiation. Nat. Rev. Mol. Cell Biol. 5, 471-480 (2004).

30. Schilmiller, A. L., Last, R. L. \& Pichersky, E. Harnessing plant trichome biochemistry for the production of useful compounds. Plant J. 54, 702-711 (2008).

31. Walker, A. R. et al. The TRANSPARENT TESTA GLABRA1 locus, which regulates trichome differentiation and anthocyanin biosynthesis in Arabidopsis, encodes a WD40 repeat protein. Plant Cell 11, 1337-1350 (1999).

32. Bouyer, D. et al. Two-dimensional patterning by a trapping/depletion mechanism: the role of TTG1 and GL3 in Arabidopsis trichome formation. PLoS Biol. 6, e141 (2008).

33. Gowda, N. K., Kandasamy, G., Froehlich, M. S., Dohmen, R. J. \& Andreasson, C. Hsp70 nucleotide exchange factor Fes1 is essential for ubiquitin-dependent degradation of misfolded cytosolic proteins. Proc. Natl Acad. Sci. USA 110, 5975-5980 (2013)

34. Bachmair, A. \& Varshavsky, A. The degradation signal in a short-lived protein. Cell 56, 1019-1032 (1989).

35. Chien, J. C. \& Sussex, I. M. Differential regulation of trichome formation on the adaxial and abaxial leaf surfaces by gibberellins and photoperiod in Arabidopsis thaliana (L.) Heynh. Plant Physiol. 111, 1321-1328 (1996).

36. Bramsiepe, J. et al. Endoreplication controls cell fate maintenance. PLoS Genet. 6, e1000996 (2010).

37. Putterill, J., Robson, F., Lee, K., Simon, R. \& Coupland, G. The CONSTANS gene of Arabidopsis promotes flowering and encodes a protein showing similarities to zinc finger transcription factors. Cell 80, 847-857 (1995).

38. Simon, R., Igeno, M. I. \& Coupland, G. Activation of floral meristem identity genes in Arabidopsis. Nature 384, 59-62 (1996).

39. Onouchi, H., Igeno, M. I., Perilleux, C., Graves, K. \& Coupland, G. Mutagenesis of plants overexpressing CONSTANS demonstrates novel interactions among Arabidopsis flowering-time genes. Plant Cell 12, 885-900 (2000).

40. Volkmann, G., Volkmann, V. \& Liu, X. Q. Site-specific protein cleavage in vivo by an intein-derived protease. FEBS Lett. 586, 79-84 (2012).

41. Gray, W. M., Ostin, A., Sandberg, G., Romano, C. P. \& Estelle, M. High temperature promotes auxin-mediated hypocotyl elongation in Arabidopsis. Proc. Natl Acad. Sci. USA 95, 7197-7202 (1998).

42. Koini, M. A. et al. High temperature-mediated adaptations in plant architecture require the bHLH transcription factor PIF4. Curr. Biol. 19, 408-413 (2009).

43. Kumar, S. V. \& Wigge, P. A. H2A.Z-containing nucleosomes mediate the thermosensory response in Arabidopsis. Cell 140, 136-147 (2010).

44. Franklin, K. A. et al. Phytochrome-interacting factor 4 (PIF4) regulates auxin biosynthesis at high temperature. Proc. Natl Acad. Sci. USA 108, 20231-20235 (2011).

45. Quint, M. et al. Molecular and genetic control of plant thermomorphogenesis. Nat. Plants 2, 15190 (2016).

46. Tissier, A. Glandular trichomes: what comes after expressed sequence tags? Plant J. 70, 51-68 (2012).

47. Lange, B. M. \& Turner, G. W. Terpenoid biosynthesis in trichomes-current status and future opportunities. Plant Biotechnol. J. 11, 2-22 (2013).

48. Kliebenstein, D. J. Making new molecules-evolution of structures for novel metabolites in plants. Curr. Opin. Plant Biol. 16, 112-117 (2013).

49. Pattanaik, S., Patra, B., Singh, S. K. \& Yuan, L. An overview of the gene regulatory network controlling trichome development in the model plant, Arabidopsis. Front. Plant Sci. 5, 259 (2014).

50. Kleinboelting, N., Huep, G., Kloetgen, A., Viehoever, P. \& Weisshaar, B. GABI-Kat SimpleSearch: new features of the Arabidopsis thaliana T-DNA mutant database. Nucleic Acids Res. 40, D1211-D1215 (2012).

51. Ecker, D. J. et al. Gene synthesis, expression, structures, and functional activities of site-specific mutants of ubiquitin. J. Biol. Chem. 262, 14213-14221 (1987).

52. Bachmair, A., Becker, F., Masterson, R. V. \& Schell, J. Perturbation of the ubiquitin system causes leaf curling, vascular tissue alterations and necrotic lesions in a higher plant. EMBO J. 9, 4543-4549 (1990).

53. Gallie, D. R., Sleat, D. E., Watts, J. W., Turner, P. \& Wilson, T. M. A comparison of eukaryotic viral 5'-leader sequences as enhancers of mRNA expression in vivo. Nucleic Acids Res. 15, 8693-8711 (1987).

54. Kanemaki, M., Sanchez-Diaz, A., Gambus, A. \& Labib, K. Functional proteomic identification of DNA replication proteins by induced proteolysis in vivo. Nature 423, 720-724 (2003).
55. Sanchez-Diaz, A., Kanemaki, M., Marchesi, V. \& Labib, K. Rapid depletion of budding yeast proteins by fusion to a heat-inducible degron. Sci. STKE 2004, PL8 (2004).

56. Jakoby, M. J. et al. Analysis of the subcellular localization, function, and proteolytic control of the Arabidopsis cyclin-dependent kinase inhibitor ICK1/KRP1. Plant Physiol. 141, 1293-1305 (2006).

57. Rademacher, T. et al. An engineered phosphoenolpyruvate carboxylase redirects carbon and nitrogen flow in transgenic potato plants. Plant J. 32, 25-39 (2002)

58. Kertbundit, S., De Greve, H., Deboeck, F., Van Montagu, M. \& Hernalsteens, J P. In vivo random beta-glucuronidase gene fusions in Arabidopsis thaliana. Proc. Natl Acad. Sci. USA 88, 5212-5216 (1991).

59. Lucast, L. J., Batey, R. T. \& Doudna, J. A. Large-scale purification of a stable form of recombinant tobacco etch virus protease. Biotechniques 30, 544-556 (2001).

60. Sikorski, R. S. \& Hieter, P. A system of shuttle vectors and yeast host strains designed for efficient manipulation of DNA in Saccharomyces cerevisiae. Genetics 122, 19-27 (1989).

61. Kurian, L., Palanimurugan, R., Godderz, D. \& Dohmen, R. J. Polyamine sensing by nascent ornithine decarboxylase antizyme stimulates decoding of its mRNA. Nature 477, 490-494 (2011).

62. Koncz, C. \& Schell, J. The promoter of TL-DNA gene 5 controls the tissuespecific expression of chimaeric genes carried by a novel type of Agrobacterium binary vector. Mol. Gen. Genet. 204, 383-396 (1986).

63. Dissmeyer, N. \& Schnittger, A. Use of phospho-site substitutions to analyze the biological relevance of phosphorylation events in regulatory networks. Methods Mol. Biol. 779, 93-138 (2011).

64. Voinnet, O., Rivas, S., Mestre, P. \& Baulcombe, D. An enhanced transient expression system in plants based on suppression of gene silencing by the p19 protein of tomato bushy stunt virus. Plant J. 33, 949-956 (2003).

65. Echalier, G. \& Ohanessian, A. Isolement, en cultures in vitro, de lignées cellulaires diploïdes de Drosophila melanogaster. C. R. Acad. Sci. (Paris) 268, 1771-1773 (1969).

66. Schneider, I. Cell lines derived from late embryonic stages of Drosophila melanogaster. J. Embryol. Exp. Morphol. 27, 353-365 (1972).

67. Bischof, J., Maeda, R. K., Hediger, M., Karch, F. \& Basler, K. An optimized transgenesis system for Drosophila using germ-line-specific phiC31 integrases. Proc. Natl Acad. Sci. USA 104, 3312-3317 (2007).

68. Kim, K. W., Franceschi, V. R., Davin, L. B. \& Lewis, N. G. Beta-glucuronidase as reporter gene: advantages and limitations. Methods Mol. Biol. 323, 263-273 (2006).

69. Jefferson, R. A., Kavanagh, T. A. \& Bevan, M. W. GUS fusions: betaglucuronidase as a sensitive and versatile gene fusion marker in higher plants. EMBO J. 6, 3901-3907 (1987).

70. Dissmeyer, N. et al. T-loop phosphorylation of Arabidopsis CDKA;1 is required for its function and can be partially substituted by an aspartate residue. Plant Cell 19, 972-985 (2007).

71. Dissmeyer, N. et al. Control of cell proliferation, organ growth, and DNA damage response operate independently of dephosphorylation of the Arabidopsis Cdk1 homolog CDKA;1. Plant Cell 21, 3641-3654 (2009).

\section{Acknowledgements}

This work was supported by a grant for a Junior Research Group of the ScienceCampus Halle-Plant-based Bioeconomy to N.D.; by a PhD fellowship of the Landesgraduiertenförderung Sachsen-Anhalt and a grant of the German Academic Exchange Service (DAAD) awarded to F.F.; grants from the EMBO Young Investigator Programme (YIP) and the Action Thématique et Incitative sur Programme (ATIP) from the Centre National de la Recherche Scientifique (CNRS) to A.S. Financial support comes from the state of Saxony Anhalt, the Deutsche Forschungsgemeinschaft (DFG), Graduate Training Center GRK1026 'Conformational Transitions in Macromolecular Interactions' at Halle and the Leibniz Institute of Plant Biochemistry (IPB) at Halle, Germany. The GABI-Kat project (German Plant Genomics Program-Kölner Arabidopsis T-DNA lines) provided the ttg1 T-DNA line via NASC-The European Arabidopsis Stock Centre. We thank Dieter Lange for assistance in western blotting, Petra Majovsky for LC-MS analyses, Hugo Stocker for his advice and Angela Baer and Anna Maria Strässle Eugster for technical support during the fly work. We are thankful to Petra Jansen, Sabine Voigt and Philipp Plato for their excellent greenhouse support at Halle. We thank Annika K. Weimer for constant support; Andreas Bachmair for the prt1 mutant and initial discussions; Luz Irina A. Calderón Villalobos, Moritz K. Nowack, Nikolay Rozhkov, Christof Taxis, Michael Knop, Masato Kanemaki and the members of N.D.'s lab for advice and comments on the manuscript. The publication of this article was funded by the Open Access fund of the Leibniz Association.

\section{Author contributions}

N.D. and A.S. planned the project and N.D. wrote the manuscript and compiled the display items; N.D. designed the degron cassettes, tested and identified the functional lt-degron cassette and performed plant and protein work for TTG1 and CO together with T.R.; F.F. contributed the GUS, TEV and GFP work in Arabidopsis; S.M. and 
F.F. contributed protein work in tobacco and transcript analyses; N.D. contributed the developmental and protein analysis of TTG1 and CO. K.N. prepared and performed experiments in cell culture together with F.F.; K.N. prepared and performed experiments in Drosophila flies together with I.A.; M.S.F., J.H. and R.J.D. contributed mutant DHFR variants; R.J.D. planned and tested the S. cerevisiae constructs; W.H. analysed protein samples by LC-MS; W.B. modelled the DHFR variants. All authors discussed the results and contributed in the finalization of the manuscript. Responsibility for figures and related experiments: Figs 1a,b,c,e, 2a,b and 3b, and Supplementary Figs 1, 2, 3b,c,d,f,g, 5 and 7, N.D.; Figs 1f, 3c, 4, 5 and $7 \mathrm{a}-\mathrm{c}$, and Supplementary Figs $3 \mathrm{e}, 4,6$ and 7a,b, F.F.; Figs 1d, 2c and 3a, and Supplementary Figs 3a,b, T.R.; Fig. 5 and Supplementary Figs $3 \mathrm{e}$ and 4a-c,e,g, S.M.; Fig. 6, R.J.D., M.S.F., J.H.; Fig. 7d, I.A., K.N.; Supplementary Fig. 5a-c,e-i, W.B.; Supplementary Fig. 7c, W.H.

\section{Additional information}

Supplementary Information accompanies this paper at http://www.nature.com/ naturecommunications

Competing financial interests: The Technology Offices at the Leibniz Institute of Plant Biochemistry (IPB) and at the Centre national de la recherche scientifique (CNRS) have filed a patent application on behalf of N.D. and A.S. based on the findings described in this manuscript. The remaining authors declare no competing financial interests.

Reprints and permission information is available online at http://npg.nature.com/ reprintsandpermissions/

How to cite this article: Faden, F. et al. Phenotypes on demand via switchable target protein degradation in multicellular organisms. Nat. Commun. 7:12202 doi: $10.1038 /$ ncomms12202 (2016).

\section{(ㄷ) (1)}

This work is licensed under a Creative Commons Attribution 4.0 International License. The images or other third party material in this article are included in the article's Creative Commons license, unless indicated otherwise in the credit line; if the material is not included under the Creative Commons license, users will need to obtain permission from the license holder to reproduce the material. To view a copy of this license, visit http://creativecommons.org/licenses/by/4.0/

(C) The Author(s) 2016 